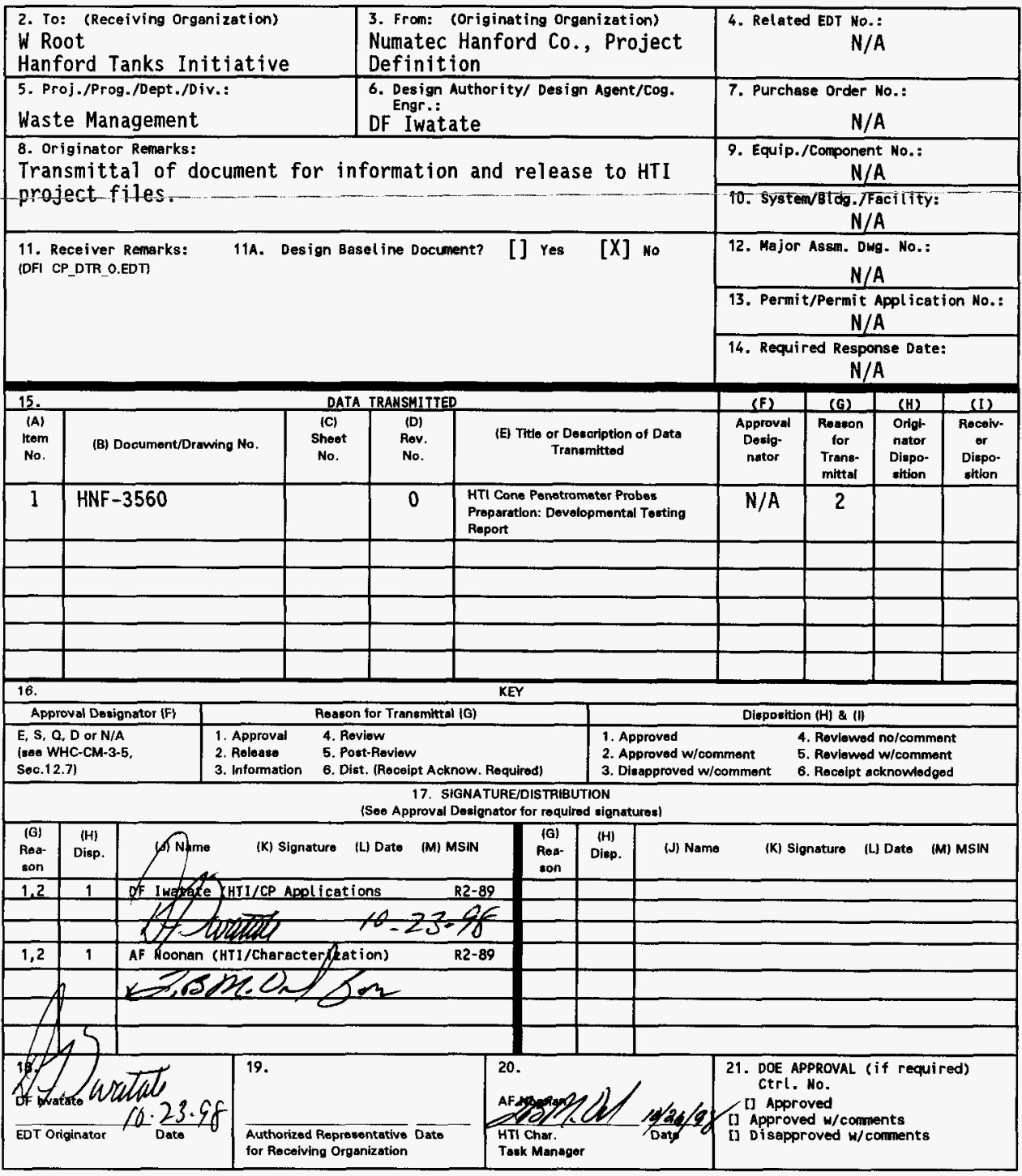

BD-7400-172-2 (05/96) GEF097 (DFI CP_DTR_0.EDT) 
HNF-3560, Rev. 0

\section{HTI Cone Penetrometer Probes Preparation: Developmental Testing Report}

DF Iwatate

Numatec Hanford Company, Richland, WA 99352-1300

U.S. Department of Energy Contract DE-AC06-96RL13200

EDT/ECN: $622818 \quad$ UC: 2030

Org Code: 73500 CACN: 103262 (CP Probe Deployment Prep)

B\&R Code: EW3130010 Total Pages: 73

Key Words: Single-Shell Tanks, waste, leakage plume, cone penetrometer, $C P$, gamma, xray fluorescence, :vadose zone, soil, soil sampling, $A X-104$, training, development testing

Abstract: The HTI subsurface characterization task will use the Hanford Cone Penetrometer platform (CPP) to deploy soil sensor and sampling probes into the vadose zone/soils around $A X-104$ during FY-99. This report provides the data and information compiled during during vendor field development tests and laboratory/bench checkout. This document is a vendor deliverable item identified in the ARA Statement of Work HNF2881, Revision 1. This version of the DTR includes "to-be-determined" items and some incomplete sections. The Rev. 0 is being released to support the concurrent task of procedure preparation and Qualification Test Plan preparation. Revision 1 is planned to contain all data and information.

(CP_DTR_O.CVR)

TRADEMARK DISCLAIMER. Reference herein to any specific commercial product, process, or service by trade name, trademark, manufacturer, or otherwise, does not necessarily constitute or inply its endorsement, recommendation, or favoring by the United states Government or any agency thereof or its contractors or subcontractors.

Printed in the United States of America. To obtain copies of this document, contact: Document Control Services, P.0. Box 950, Mailstop H6-08, Richland WA 99352, Phone (509) 372-2420;

Fax (509) 376-4989.
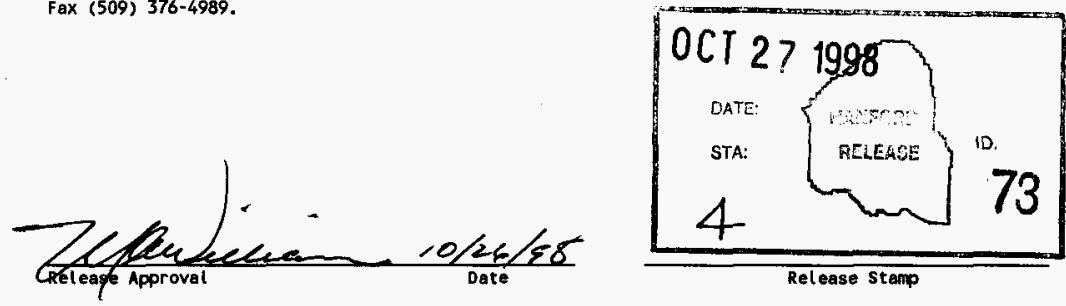

Approved for Public Release 


\section{HANFORD TANK INITIATIVE CONE PENETROMETER VADOSE ZONE CHARACTERIZATION PROJECT}

HTI Cone Penetrometer Probes Preparation:

Developmental Test Report

$$
\text { Prepared by: }
$$

Applied Research Associates, Inc.

Pacific Northwest Branch

3250 Port of Benton Blvd.

Richland, WA 99352

Contract Number MJG-SLB-A52807

Work Element \#3

Revision 0.0

October 25, 1998 


\section{Table of Contents}

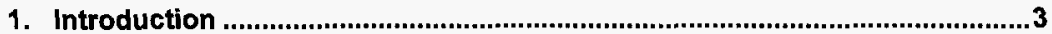

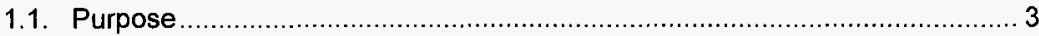

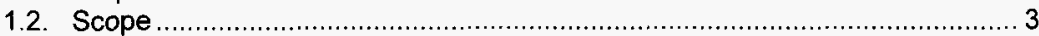

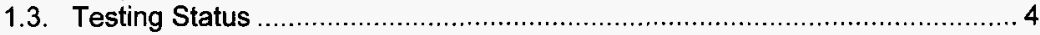

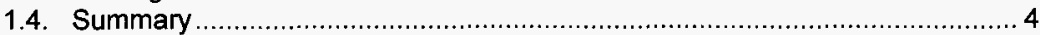

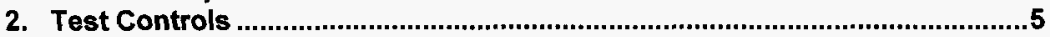

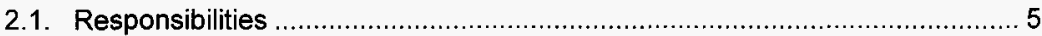

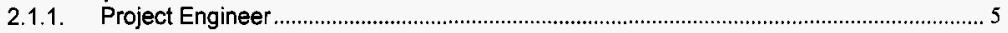

2.1.2. Applied Research Associates, Inc. Test Performers (or associated subcontractors) ..... 5

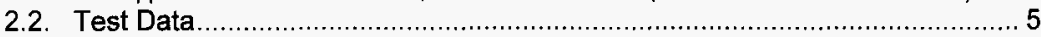

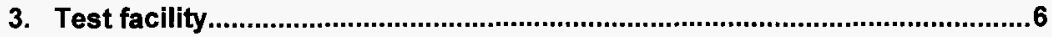

4. TEST Procedures and results ...............................................................6

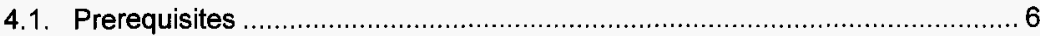

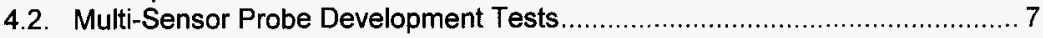

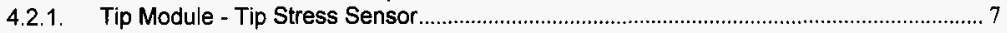

4.2.2. Tip Module - Sleeve Stress Sensor ……........................................................................ 8

4.2.3. Tip Module - Soil Stratigraphy from the Tip \& Sleeve Sensors ....................................... 9

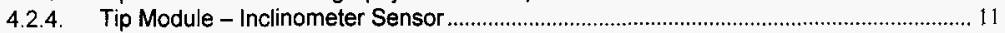

4.2.5. Tip Module - Magnetometer Sensor ................................................................................... 12

4.3. Soil Moisture \& Resistivity (SMR) Module Development Tests ................... 14

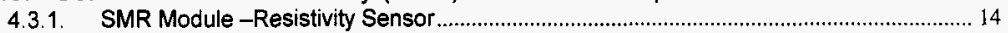

4.3.2. SMR Module -Soil Moisture Sensor ............................................................................. 15

4.4. Gamma and XRF Module Development Tests................................. 16

4.4.1. Gamma and XRF Module - Temperature Test ............................................................. 16

4.4.2. Gamma and XRF Module - Gamma Energy Range Test............................................... 20

4.4.3. Gamma and XRF Module - Gamma Throughput Test ...................................................23

4.4.4. Gamma Module -Efficiency Testing ................................................................................26

4.4.5. Gamma \& XRF Module -Hanford Soil matrix sample Testing .........................................29

4.5. Soil Sampler Probe Development Tests ...................................... 33

4.5.1. Soil Sampler Probe - Latching Mechanism ..................................................................... 33

4.5.2. Soil Sampler Probe - Inclinometer Sensor....................................................................... 34

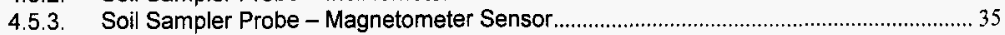

Attachment 1 - Tip Module Calibration \& Verification Information .....................37

Attachment 2 - Soil Moisture Calibration Information..........................................53

Attachment 3 - Gamma Temperature Correction Algorithm ............................62

Attachment 4 - Soil Sampler Probe Information ................................................68 


\section{HTI CONE PENETROMETER PROBE ENGINEERING}

\section{INTRODUCTION}

\subsection{Purpose}

This report documents the development testing of the Multi-Sensor Probe (MSP) and its associated Data Acquisition system (MSP-DAS) as well as the Soil Sampler Probe (SSP) and it corresponding magnetometer and inclinometer modules (M\&I) for the HTI CPT vadose zone characterizations project. The MSP probe includes a variety of sensors including: 1) a tip module containing tip stress, sleeve stress and inclination sensor as well as a magnetometer for detection of ferrous objects, 2) a soil moisture and resistivity module, 3) a gamma spectroscopy (GS) and X-Ray Fluorescence (XRF) module for radiation characterization and detection of metal contaminants. The probe operates in conjunction with the Hanford Cone Penetrometer Platform (CPP), the cone data acquisition system (CPP-DAS), and the Multi-Sensor Probe (MSP) data acquisition system (MSP-DAS). The SSP consists of a latching mechanism that allows either the M\&I tip unit or a sample chamber to be loaded into the rods without removal of the push rods.

The testing which has been conducted demonstrates the overall system function as well as system integration, including software integration with the Cone Penetrometer Platform (CPP) data acquisition system (CPP-DAS) for both probes. This document details the procedures used to conduct these tests and confirm that the specifications detailed in HNF-2881, Rev. 1 entitled "Development, Fabrication and Performance Goals for HTI Demonstration Cone Penetrometer Probes" are satisfied.

\subsection{Scope}

Completion of the testing specified in this document will verify that the mechanical, electrical and software components of the MSP, MSPDAS, and SPP are operating as designed and meet the specifications to the largest extent possible in the statement of work. The scope of the test plan is as follows:

- Basic equipment functions and mechanical interfaces will be verified.

- Performance of electrical components and sensor responses will be verified. 
- The software and software interfaces between the MSP-DAS and CPP-DAS will be demonstrated.

\subsection{Testing Status}

This document covers the development testing for both the MSP and SSP probes. The development testing covered in this report has been conducted over a period of two months as various components of the system reached an appropriate stage for testing. The results presented in this report represent those that were complete and ready as of 10/23/98. A few items remain to be tested to complete this report. One such item is the XRF sensor. Some testing of the XRF sensor was conducted during the North Carolina test sequence, but the sensor that was in the probe at that time has subsequently stopped working and been replaced. Therefore, it has been decided to repeat the testing to document and determine the performance of the new sensor. For these reasons, some items may be listed at TBD.

\subsection{Summary}

In general, the results from the development testing have been satisfactory. Some of the major highlights include successful completion of a development push of the MSP at Hanford to a depth of 25 feet prior to September 25, 1997. This accomplished a major milestone of the cone penetrometer project. Other highlights are a CPT based gamma spectroscopy tool with a resolution of 7.5 percent. This resolution is one percent lower than that required by the specification. Testing of the gamma module indicates that the minimum detection limit for Cs-137 is $11.5 \mathrm{pCi} / \mathrm{gm}$ in Hanford Soils. The MSP probe has also been used to determine the soil stratigraphy and volumetric moisture content of the soils that have been penetrated. These results are being compared with other information for the test site and additional information will be available in the future.

Concerning the SSP, the latching mechanism has been redesigned and the new design has been highly successful to date. There have been no instanced where the latch has either been locked in place when it should be unlocked or refused to lock in at depth. This advancement represents a first for the CPT industry. 


\section{TEST CONTROLS}

\subsection{Responsibilities}

\subsubsection{Project Engineer}

Deborah Iwatate

William Callaway

Gary Troyer

- Monitor testing for compliance with the test procedures and cosign the appropriate steps. (Note: On certain steps, the project engineer may run these steps to gain a better understanding of the equipment.)

- Make redline changes to working TP as required.

- Can authorize the test performer to perform Project Engineer responsibilities on a limited basis.

\subsubsection{Applied Research Associates, Inc. Test Performers (or associated subcontractors) \\ Wesley Bratton \\ Steve Timian \\ Bill Dunn \\ Willie Dickerson}

- Develop working test plan.

- Overall responsibilities for maintaining and controlling developmental testing.

- Perform test in accordance with working test procedure.

- Provide liaison with facility used for testing.

- Maintain a file of documented information pertinent to the tests.

- Assure safe conduct of testing.

- Prepare test report.

\subsection{Test Data}

All test data, pertinent observations, and off-normal events shall be recorded in notebooks. In addition, data may also be recorded on the 
observation/results data sheets. Some of these are presented in this test report (TR). The data recorded during the test shall be released in the TR as raw or reduced data. Calibration data shall be released in the TR.

\section{TEST FACILITY}

The qualification/verification test program was conducted as a series of individual test sequences in a variety of locations. The bench testing for verification of the tip module and the soil moisture/resistivity modules described in this plan was conducted at the New England Division offices of ARA in South Royalton, Vermont. Due to the nature of the work involved for the performance characterization of the gamma and XRF unit, this test sequence was performed at Quantum Research Services (an ARA subcontractor) in Durham, NC. The final aspect of the development testing was conducted at the Hanford Facility in Richland using the CPP system. This testing documented proper operation in Hanford soils as required by the specification. This test report documents the testing results from all three locations.

For the soil sampling probe all testing was conducted at Hanford to ensure proper operation in the soils of interest. The M\&I unit utilizes electronics that are specific to the CPP platform and therefore were tested only at Hanford.

\section{TEST PROCEDURES AND RESULTS}

\subsection{Prerequisites}

The goal of the developmental test program is to perform functional testing as described in the following procedures. As part of this testing, a variety of measurements were made and recorded. This information typically was recorded in the pages of laboratory notebooks as well as on computers. This computer data is further reduced and appropriate printouts of the representative data have been prepared for this report. 


\subsection{Multi-Sensor Probe Development Tests}

\subsubsection{Tip Module - Tip Stress Sensor}

PURPOSE:

Demonstrate integration of the tip stress sensor in the MSP (4.1.1). The tip sensor shall be calibrated with the sensitivity provided and entered into the CPP-DAS. Tip stress should have an operating range of 0 to $10,000 \mathrm{lbs}(4.1 .3)$.

EQUIPMENT CONDITIONS:

MSP \#1 was calibrated by the vendor using the MSP tip and sleeve stress calibration procedure. The calibration was then verified using the reference load cell that is owned by the CPP platform.

TEST DATE:

$8 / 18 / 98$

\section{TEST}

The MSP module is loaded into the head clamp of a skid mounted CPT unit. The reference load cell was placed on a loading plate and connected to the CPP data acquisition system (CPP-DAS v1.34). A loading cup was placed on top of the load cell to receive and center the cone tip on the load cell. Using the hydraulic cylinders, the MSP probe was lowered until just above the load cell. CPP-DAS software was started and the verification module initiated. Once the baseline readings were taken for both the tip and the load cell, the hydraulic cylinders were used to load the tip stress sensor on the load cell. The load was held as constant as possible above a level of $5000 \mathrm{lbs}$. The CPP-DAS software displayed readings from both the MSP tip stress sensor and the reference load cell. The space bar was pushed to record a single reading for both sensors. The percent difference between the tip stress sensor and the load cell was calculated. The software indicates that the sensor passed the verification test if the percent difference is less than 2 percent. The readings for the tip stress load, the reference load cell load and the percent difference were recorded in the lab books.

\section{EXPECTED:}

Tip Stress Sensor: Measured load consistent with both vendor calibration as well as the reference load cell. Responses must be within 2 percent of measured reference load. 
TEST RESULT(S):

Tip Stress Calibration Plot attached along with reference load cell calibration and traceability to NIST standards in Attachment 1.

$\begin{array}{llll} & \text { Test \#1 } & \text { Test \#2 } & \text { Test \#3 } \\ \text { MSP tip stress } & 10,450 \mathrm{lbs} & 10,400 \mathrm{lbs} & 8,644 \mathrm{lbs} \\ \text { Reference load cell } & 10,460 \mathrm{lbs} & 10,370 \mathrm{lbs} & 8,678 \mathrm{lbs} \\ \text { Percent difference } & 0.10 \% & 0.29 \% & -0.39 \%\end{array}$

The tip stress sensor verified all three times it was tested.

\subsubsection{Tip Module - Sleeve Stress Sensor}

PURPOSE:

Demonstrate integration of the sleeve stress sensor in the MSP (4.1.1). Sensor shall be calibrated with the sensitivity provided and entered into the CPP-DAS. Sleeve stress should operate over a range of 0 to $8500 \mathrm{lbs}(4.1 .4)$.

\section{EQUIPMENT CONDITIONS:}

The MSP \#1 was calibrated by the vendor using the MSP tip and sleeve stress calibration procedure. The calibration was then verified using the reference load cell that is owned by the CPP platform.

\section{TEST DATE:}

$8 / 18 / 98$

TEST:

The MSP module is loaded into the head clamp of a skid mounted CPT unit. The reference load cell was placed on a loading plate and connected to the CPP data acquisition system. A loading cup was placed on top of the load to receive and center the cone tip on the load cell. The tip and magnetometer modules were removed from the MSP. A balancing resistor was attached to the magnetometer wires. Using the hydraulic cylinders, the MSP probe was lowered until just above the load cell. CPP-DAS software (V1.34) was started and the verification module initiated. Once the baseline readings were taken for both the sleeve and the reference load cell, the hydraulic cylinders were used to load the sleeve stress sensor on the load cell. The load was held as constant as possible above a level of $5000 \mathrm{lbs}$. The CPPDAS software displayed readings for both the MSP sleeve stress sensor and the reference load cell. The space bar was pushed to 
record a single reading for both sensors. The percent difference between the sleeve stress sensor and the load cell was calculated. The software indicates that the sensor passed the verification test if the percent difference is less than 2 percent. The readings for the sleeve stress load, the reference load cell load, and the percent difference were recorded in the lab books.

\section{EXPECTED:}

Sleeve Stress Sensor: Measured load consistent with both vendor calibration as well as the reference load cell. Responses must be within 2 percent of measured reference load.

TEST RESULT(S):

Sleeve Stress Calibration Plot attached along with reference load cell calibration and traceability to NIST standards in Attachment 1.

$\begin{array}{llll} & \text { Test \#1 } & \text { Test \#2 } & \text { Test \#3 } \\ \text { MSP sleeve stress - } & 5,969 \mathrm{lbs} & 7,111 \mathrm{lbs} & \mathbf{8 , 1 9 7} \mathrm{lbs} \\ \text { Reference load cell - } & 6,083 \mathrm{lbs} & 7,002 \mathrm{lbs} & 8,052 \mathrm{lbs} \\ \text { Percent difference - } & -1.87 \% & 1.55 \% & 1.80 \%\end{array}$

The sleeve stress sensor verified all three times it was tested.

\subsubsection{Tip Module - Soil Stratigraphy from the Tip \& Sleeve Sensors}

\section{PURPOSE:}

Demonstrate data reduction of tip and sleeve stress sensors into soil stratigraphy profiles.

\section{EQUIPMENT CONDITIONS:}

The MSP \#1 was calibrated by the vendor using the MSP tip and sleeve stress calibration procedure. The calibrations were then verified using the reference load cell that is owned by the CPP platform. The probe was pushed to a depth of 25 feet in Hanford soils using the CP Platform and CPP-DAS v 1.37.

\section{TEST DATE:}

9/24/98

\section{TEST:}

The test was conducted at the ILAW site of the Hanford facility. The probe was pushed to a depth of 25.5 feet using the developed 
procedures of operation under the HTI program. The probe was stopped every 1.5 feet to record gamma and $x$-ray spectra. After the test was conducted, the data was reduced using Cone-tap and ConeGraph software to produce profiles of the tip and sleeve sensors as well as soil stratigraphy profiles. The soil types were determined from the CPT data using a procedure developed by Robertson, 1990 and coded by ARA into Cone-tap.

\section{EXPECTED:}

Tip and sleeve stress profiles as a function of depth as well as soil type and stratigraphy.

\section{TEST RESULT(S):}

The raw data file for the penetration is saved in "Z24s9804C.dat" and the boring ID is "B8712". The profiles of the tip and sleeve stress sensors as well as the determined soil stratigraphy are presented Figure 1. The soil stratigraphy shows various layers of sands and sandy gravel intermixed with dense, finer grained materials that classify as over consolidated.
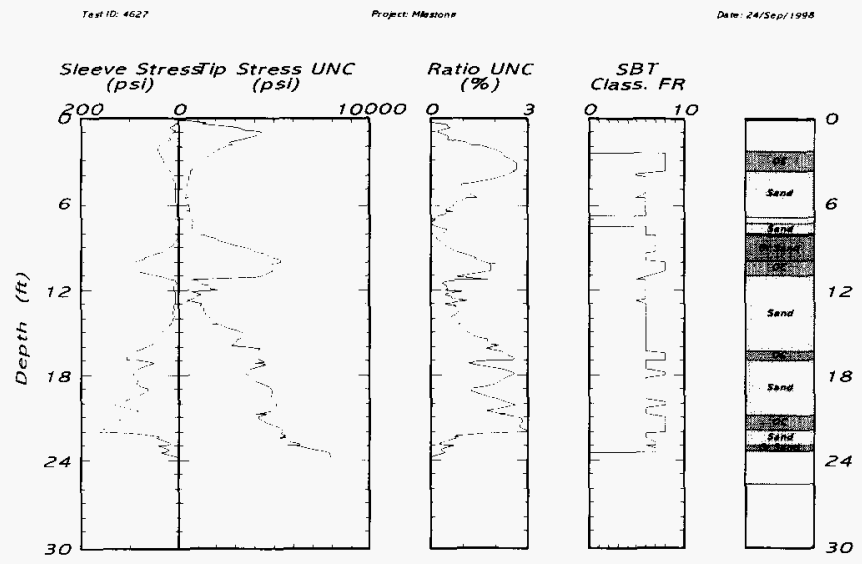

Class FR: Friction Ratio Classification (Ref: Robertson 1990)

Figure 1 - Tip and sleeve stress profiles from a 25-foot penetration using MSP\#1. Figure also presents the soil stratigraphy calculated from the tip and sleeve profiles. 


\subsubsection{Tip Module - Inclinometer Sensor}

\section{PURPOSE}

Demonstrate presence of a two-axis inclinometer sensor (4.3.2), which measures angle of deflection off vertical in both an $X$ and $Y$ direction. The sensor shall have a reading range of $\pm 15^{\circ}$ with a linearity of $0.5 \%(4.3 .1)$.

\section{EQUIPMENT CONDITIONS:}

MSP \#1 was calibrated by the vendor using the MSP inclinometer calibration procedure. The calibration was then verified using the inclinometer verification jig and a "smart level" brand digital level. The "smart level" was checked using a set of reference angle blocks.

\section{TEST DATE:}

$$
9 / 16 / 98
$$

TEST:

The test was conducted at the ILAW site of the Hanford facility. The probe was placed in the inclinometer calibration jig at an approximate angle of 10 degrees. The CPP_DAS ( $v 1.37)$ software was started. Using the monitor channel option of the code, the probe was slowly rotated until the maximum value for the $\mathrm{X}$-axis inclination was determined. The probe was then locked into the jig. The probe was positioned vertically in the jig. Using the verification section of the CPP-DAS code, baseline readings are taken. The probe is then inclined to an approximate 15-degree angle. The space bar is pushed and the reading from the smart level (reference gage) is entered. Repeat the procedure for the $\mathrm{Y}$-axis verification.

\section{EXPECTED:}

The inclination recorded by the MSP probe must compare within $2 \%$ of the value from the reference gage.

\section{TEST RESULT(S):}

Both the $\mathrm{X}$-axis and $\mathrm{Y}$-axis calibration plots are attached along with the printed verification test pages (Attachment 1). The results of the verification are also presented in the following table. 
MSP Probe readings

Reference Gage

Percent Difference
$\mathrm{X}$ Axis

$-16.94^{\circ}$

$-16.8^{\circ}$

$0.76 \%$
Y Axis

$-16.4^{\circ}$

$-16.3^{\circ}$

$0.62 \%$

Figure 2 also presents profiles from the penetration conducted on $9 / 24 / 98$. This again shows the operation of the sensor in profiling the angle off vertical of the penetration in two directions.

Test id-1627

Project: Milestone

Date: 24/5ep:1998

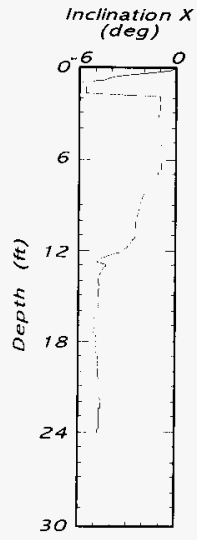

Inclination
(deg)
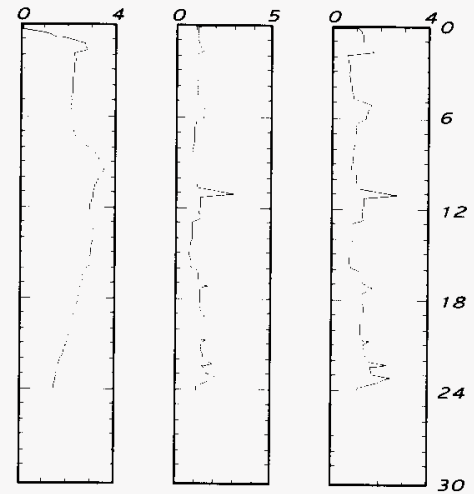

Figure 2 - Profiles of the $X$ and $Y$ inclination during the 9/24/98 penetration.

\subsubsection{Tip Module - Magnetometer Sensor}

\section{PURPOSE:}

Demonstrate presence of a magnetometer sensor in the MSP probe, which has the ability to detect the presence of the ferrous metal object ahead of the cone (4.2.1). The probe should accurate indicate the distance to the metal object at a range of 2 inches (4.2.2). 
EQUIPMENT CONDITIONS:

MSP \#1 was calibrated by the vendor using the MSP magnetometer calibration procedure. The calibration was then verified by placing the MSP probe in the head clamp and raising and lowering the probe above a metal target plate. The metal target plate for this testing was the same loading plate used for the tip and sleeve testing. The plate covers the B-clamp and provides a strong load resistance. The actual distance was measured using a standard tape measure.

TEST DATE:

$9 / 23 / 98$

TEST:

The test was conducted at the ILAW site of the Hanford facility. The probe was placed in the head clamp and positioned above the target plate. The CPP_DAS ( $v 1.37)$ software was started. Using the verification section of the CPP-DAS code, baseline readings are taken with the probe six inches above the target plate. The probe is then lowered to a position one inch above the plate. The space bar is pushed and the reading from the tape measure (reference gage) is entered. Repeat process for both the magnetometer LR and the magnetometer HR.

\section{EXPECTED:}

The distance to the plate recorded by the MSP probe must compare within $2 \%$ or $1 / 8^{\text {th }}$ of an inch of the value from the reference gage.

\section{TEST RESULT(S):}

The magnetometer calibration plot is attached along with the printed verification test page in Attachment 1 . The results of the verification are also presented in the following table.

$\begin{array}{lll} & \text { Mag LR } & \text { Mag HR } \\ \text { MSP Probe readings } & 1.123^{\prime \prime} & 1.149^{\prime \prime} \\ \text { Reference Gage } & 1.125^{\prime \prime} & 1.0^{\prime \prime} \\ \text { Percent Difference } & 1.59 \% & 14.2 \% \text { (less than } 1 / 8^{\text {th }} \text { ) }\end{array}$




\subsection{Soil Moisture \& Resistivity (SMR) Module Development Tests}

\subsubsection{SMR Module -Resistivity Sensor}

\section{PURPOSE:}

Demonstrate successful integration of the soil moisture and resistivity module (SMR) in the MSP (5.3.3).

\section{EQUIPMENT CONDITIONS:}

MSP \#1 has been previously calibrated by the vendor according to the MSP resistivity calibration procedures. A resistivity verification tool (labeled R1) is applied the probe and the measured resistivity using the CPP-DAS system will be noted. Repeat measurement at a separate resistivity level.

\section{TEST DATE}

$8 / 18 / 98$

TEST:

The calibration is verified by holding in the probe in the head clamp. The verification tool is applied to the probe, Using the switches on the verification tool a known resistivity can be selected. Using the verification section of the CPP-DAS code verify operation of the sensor. Validate at a second resistivity value.

\section{EXPECTED:}

Measured sensor response consistent with known resistivities of the resistivity verification tool: $0,10,100 \mathrm{k}$ and infinite (open circuit) Ohms.

\section{TEST RESULT(S):}

The calibration curve for the resistivity sensor is provided in Attachment \#2 along with verification sheets from the 9/24/98 test. The verification results for all four resistances of the verification jig from $8 / 18 / 98$ are presented below:

$\begin{array}{ll}\text { Verification Jig Position } & \text { Resistivity Sensor Output } \\ \text { Open } & 27 \mathrm{mv} \\ \text { 10 Ohms } & 1.247 \mathrm{~V} \\ \text { 100K Ohms } & 55 \mathrm{mv} \\ \text { 0 Ohms } & 1.246 \mathrm{~V}\end{array}$




\subsubsection{SMR Module -Soil Moisture Sensor}

\section{PURPOSE:}

Demonstrate successful integration of the soil moisture and resistivity module (SMR) in MSP that uses the apparent dielectric constant of the soil material to determine the volumetric moisture content (5.3.1). The sensor should have lower reporting limit of $<5 \%$ (5.3.2). The sensor response should be "tuned" for Hanford soil materials (5.3.5).

\section{EQUIPMENT CONDITIONS:}

MSP \#1 was placed in the CPT rig head clamp and individual rods added and pushed into soil test sample using the CPT push system. Data was recorded using CPP-DAS ( $V 1.34)$ as well as notes in the logbook.

\section{TEST DATE:}

$8 / 18 / 98$

\section{TEST:}

A 3-foot tall soil moisture test specimen was built in an 8-inch diameter sonotube. The sonotube was sealed at the bottom and approximately six holes drilled in the tube at a height of 6 inches above the bottom. These holes were equally spaced around the tube. Hanford soil was loaded into the tube with packing every six inches until the tube is filled within 8 inches from the top. The weight of all soils placed in the sonotube was determined. Water was added to the specimen at this time to saturate the soils. The specimen was allowed to drain overnight. The weight of the water added and that collected from the drain was recorded. Once the sample had drained for 18 hours, an additional 8 inches of oven dried Hanford soil was added to the top of the specimen. This soil was separated from the other soils by a thin plastic layer. Weigh the soil prior to adding to the sample. The sample was lowered into a test pit and leveled as best as possible. The CPT rig was then used to push the MSP probe completely through the sample. The MSP probe was withdrawn and the rig removed from over the test pit. The sample was carefully lifted out of the pit and taken to the laboratory. Individual samples were carefully taken every three inches over the length of the specimen for gravimetric soil moisture determinations. The sample gravimetric moisture contents were recorded on the test specimen data sheet and converted to volumetric soil moisture using the density of the sample. 


\section{EXPECTED:}

A collection of soil moisture measurements from both the probe as well as traditional laboratory methods. The individual soil moisture results from the laboratory analysis are present in Attachment 2 . These values were used to calibrate the soil moisture sensor for Hanford soils. The CPT data was recorded in file "Z16G809c.dat". The calibration curve is presented in the Attachment 2 . The calibration line is linear and the minimum reading was 3.02 percent.

\subsection{Gamma and XRF Module Development Tests}

\subsubsection{Gamma and XRF Module - Temperature Test}

\section{PURPOSE:}

Demonstrate operation of the gamma and XRF sensor over the temperature range of $4^{\circ}$ to $48^{\circ} \mathrm{C}$, with appropriate temperature compensation for the gamma to correct any temperature gain shifts (5.1.3).

\section{EQUIPMENT CONDITIONS:}

MSP \#1 was laid horizontal on a benchtop. A $1 \mu \mathrm{Ci}$ Co60 source was centered on the $\mathrm{Nal}$ crystal and the temperature control cooling/heating coil was placed over the GS Housing. Insulation was wrapped around the coil to further reduce heat losses. The MSP\#1 probe was connected through the umbilical cable to the electronics that are part of the total system. The electronics were set as described below. The temperature of the gamma sensor was recorded from a DVM used to monitor the temperature sensor output. The temperature was recorded in the logbooks.

Gamma Electronics

High Voltage: 630 volts

Coarse gain: 20

Fine Gain: 1.18

Shaping Time:

Shaping Time:

BLR: Auto

Shaping: Gaussian

AmpTek Gain:

AmpTek RTD:
XRF Electronics

EG\&G 671 Amp

Coarse Gain: 5

Fine Gain: 0.5

$1 \mu \mathrm{sec}$

$6 \mu \mathrm{sec}$

BLR: PZ

Shaping: Gaussian

1.18

Off 
TEST DATE:

$8 / 23 / 98$

TEST:

Ice water was circulated through the coil to cool the probe. Cooling occurred for approximately 1 hour. The cooling water was stopped and the temperature allowed to stabilize. Once stabilized, a gamma and XRF spectra was collected over a five-minute period.

Measurements were collected at three different temperatures.

\section{EXPECTED:}

Operation of both sensors over the range with the spectra remaining constant. For the gamma unit, the spectra must be temperature corrected to eliminate the temperature gain shift of the sensor.

\section{TEST RESULT(S):}

Measurements were made at temperatures of $283.1^{\circ} \mathrm{K}\left(10.1^{\circ} \mathrm{C}\right)$, $301.7^{\circ} \mathrm{K}\left(28.7^{\circ} \mathrm{C}\right)$, and $317.9^{\circ} \mathrm{K}\left(44.9^{\circ} \mathrm{C}\right)$. All data was collected using the MSP-DAS software. The file names of the files were Z0959601G000-0A, Z0959601G000-0C, and Z0959601G000-0D for the gamma sensor and Z0959601X000-OA, Z0959601X000-OC, and Z0959601X000-0D for the X-ray sensor respectively for each temperature. Additional spectra were collected but are not necessary for the analysis.

Since the gamma temperature was recorded manually, temperature corrections were not automatically calculated. For the gamma sensor the temperature correction routine presented in Attachment 3 has been used to analyze the sum of counts in each channel for each of the five raw gamma spectra collected at each temperature. It is assumed that the gamma temperature for each of the 5-minute collection periods was constant (Lab books indicate less than $0.4^{\circ} \mathrm{K}$ degree change over the time period.).

Figure 3 presents the uncorrected gamma spectra for each of the three temperatures. This clearly shows that a gain shift is occurring related to the temperature for each of the two cobalt peaks. Figure 4 presents the same three spectra after the temperature correction algorithm has been applied. This figure shows that the temperature correction algorithm corrects for the gain shift of the gamma spectrum, as the peaks for each temperature are now occurring at the same channel number. 
Raw Data Comparison

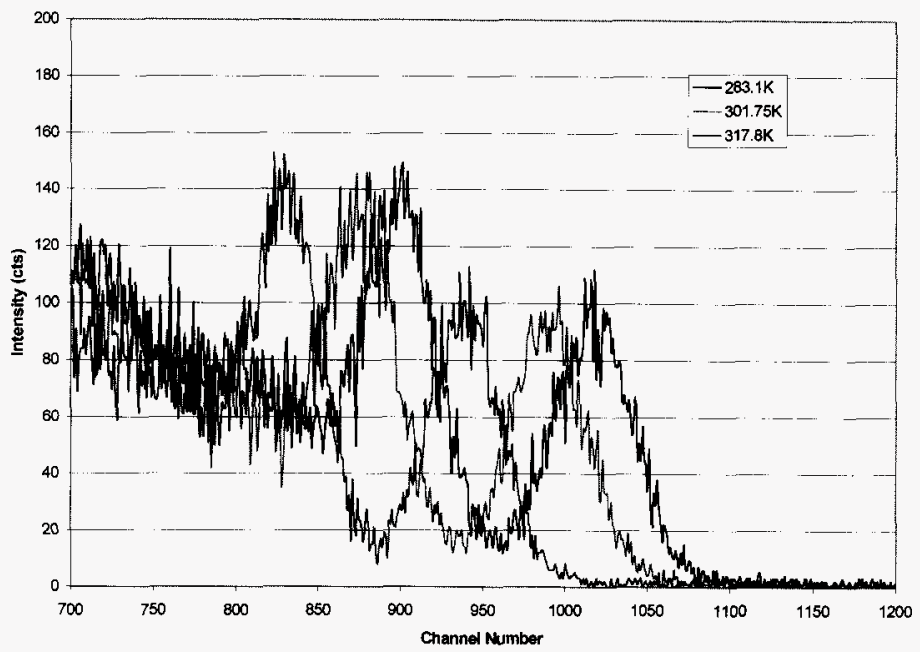

Figure 3 - Comparison of uncorrected gamma spectra at three different temperatures.

For the XRF sensor, the actual detector is placed on an independent cooler that attempts to maintain a temperature of $-30^{\circ} \mathrm{C}$ at all times. The temperature of the cooler can be monitored using a DVM plugged into the PX2T power supply. Figure 5 presents a time history of the XRF temperature as well as the gamma temperature. As the probe warms up the XRF temperature also increases, indicating that the XRF cooler is not quite keeping up, especially above $308^{\circ} \mathrm{K}$ for a probe temperature. Since the detector is cooled, large gain shifts are not expected, and therefore, no temperature correction has been developed for the XRF sensor. Figure 6 presents the three XRF spectra. It was expected that all three spectra would overlay, however the spectra at $317^{\circ} \mathrm{K}$ did not overlay. The two spectra at 283 and $301^{\circ} \mathrm{K}$ did overlay as expected. This should be investigated further with additional testing at the upper temperature range of the probe. 


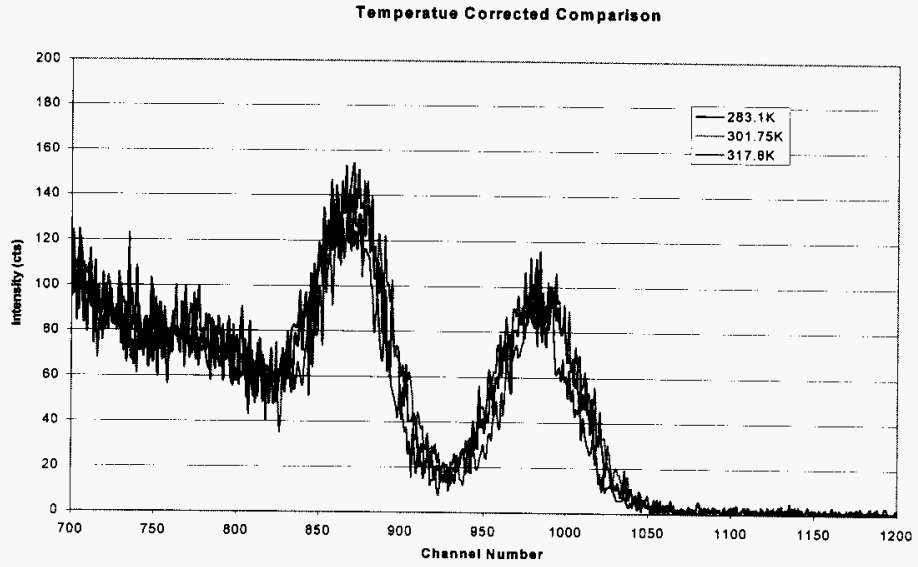

Figure 4 - Comparison of temperature corrected spectra at three separate temperatures.

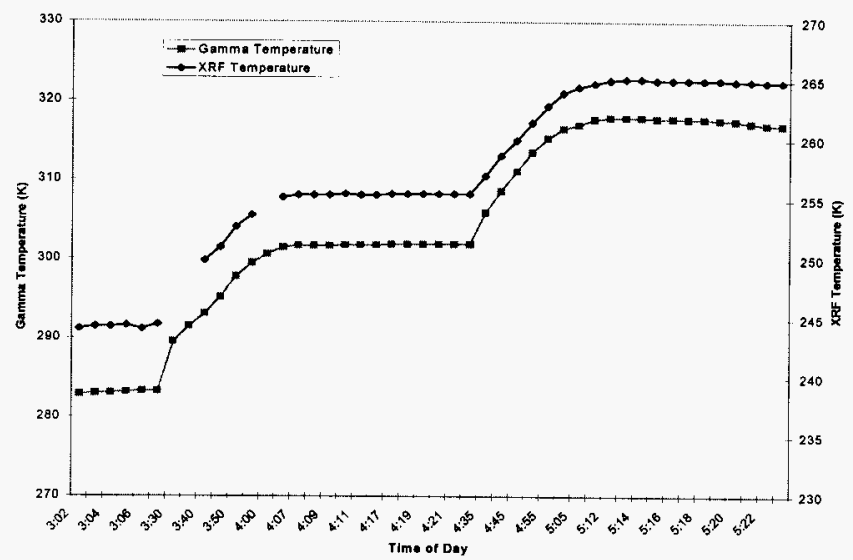

Figure 5 - Time history of Gamma and XRF temperature during the temperature testing. 
XRF Temperature comparison

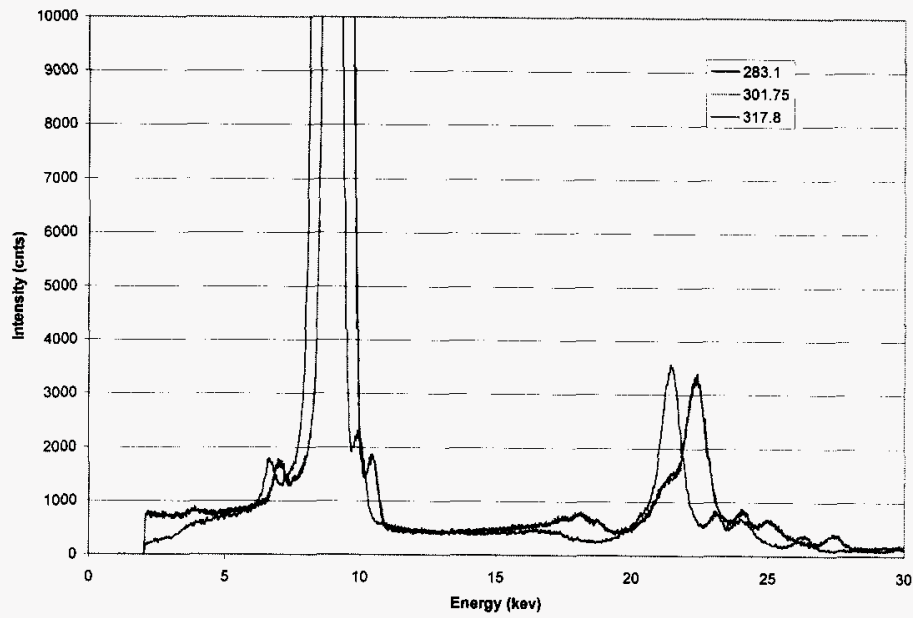

Figure 6 - Comparison of XRF spectrums at three difference temperatures. All three spectra should overlay, but the $317^{\circ} \mathrm{K}$ spectra exhibits a gain shift.

\subsubsection{Gamma and XRF Module - Gamma Energy Range Test}

PURPOSE:

Demonstrate the capability of the Gamma Sensor to measure gamma radiation in the energy range of 100 to $2700 \mathrm{keV}(5.1 .4 \& 5.16)$.

Determine the resolution of the $\mathrm{Nal}$ Crystal (5.1.7) and a linear energy calibration (5.1.8 \& 5.1.11).

\section{EQUIPMENT CONDITIONS:}

The MSP \#1 was laid horizontal on a benchtop. The gamma check source holder with the calibration sources in place was centered on the $\mathrm{Nal}$ crystal. The three sources in the holder were a $1 \mu \mathrm{Ci} \mathrm{Cs}-137$ (488-34-6), a $1 \mu \mathrm{Ci} \mathrm{Co-60} \mathrm{source} \mathrm{(1U511)} \mathrm{and} \mathrm{a} 0.1 \mu \mathrm{Ci} \mathrm{Th}-288$ (43393-2). The Cs source was aligned axially with the XRF window. The MSP\#1 probe was connected through the umbilical cable to the 
electronics that are part of the total system. The electronics were set as described below.

Gamma Electronics

High Voltage: 630 volts

Coarse gain: 20

Fine Gain: $\quad 1.18$

Shaping Time:

Shaping Time:

BLR : Auto

Shaping :

Shaping :

AmpTek Gain:

AmpTek RTD:
XRF Electronics

EG\&G 671 Amp

Coarse Gain: 5

Fine Gain: $\quad 0.5$

$1 \mu \mathrm{sec}$

$6 \mu \mathrm{sec}$

BLR : PZ

Gaussian

Gaussian

1.18

Off

TEST DATE:

$8 / 23 / 98$

TEST:

A 300-second spectrum was collected with the sources in place.

EXPECTED:

Corresponding peaks in the spectrum at energy levels of 662,1173 , 1333 , and $2614 \mathrm{keV}$.

TEST RESULT(S):

The corresponding spectrum was collected using the Maestro Software and is stored in file "3cal01". Figure 7 presents the plotted spectrum. The table below presents the ROI report from Maestro.

Table 1 - Check Standard Gamma measurements from file 3Cal01.chn

Detector \#1 ACQ 23-Aug-1998 at 9:51:47 RT = 965.1 LT $=900.0$ MSPDAS MCB 1

\begin{tabular}{|r|r|r|r|r|r|r|r|r|} 
ROI\# & & RANGE & $(\mathrm{keV})$ & GROSS & NET & $+/$ - & CENTROID & FWHM \\
\hline 1 & Cs & 608.44 & 733 & 317389 & 116571 & 1740 & 661.92 & 50.03 \\
\hline 2 & Co & 1103.78 & 1239.67 & 128642 & 65759 & 1025 & 1172.62 & 61.56 \\
\hline 3 & Co & 1263.06 & 1409.2 & 89614 & 62935 & 715 & 1331.59 & 70.15 \\
\hline 4 & Th & 2510.75 & 2708.83 & 3310 & 1840 & 186 & 2614 & 7.63
\end{tabular}




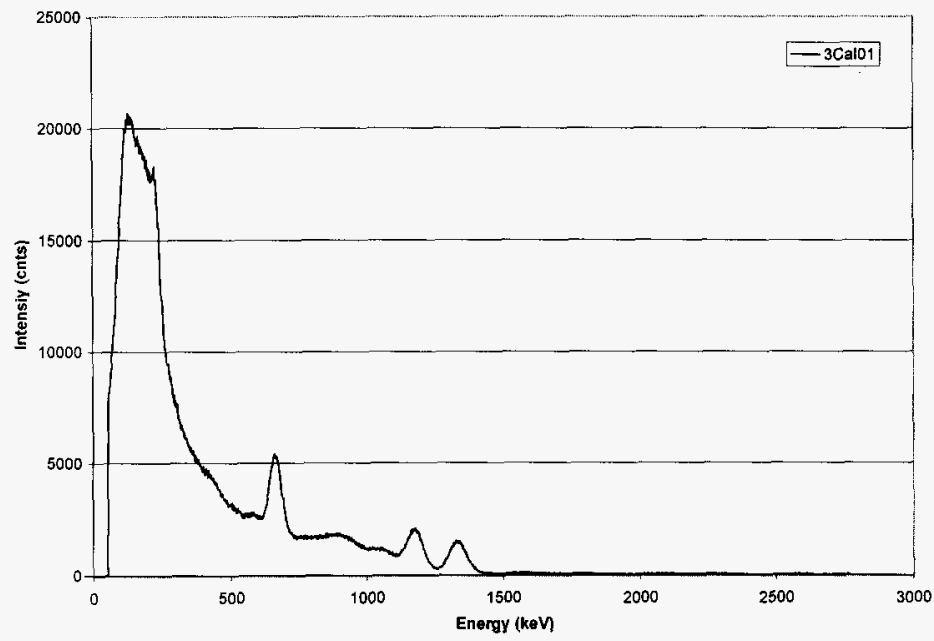

Figure 7 - Spectrum showing check standard sources from file 3Cal01.

Peaks are identified at each of the expected energy levels. Background readings on the spectrum show that the energy collection range covers 55.93- $2804 \mathrm{keV}$. Using the Maestro ROI information, the resolution of the CS peak can be calculated as $(50.03 / 662) 7.5 \%$. Plotting the centroid energy value verse, the channel number as shown in Figure 8 shows an energy calibration. A line has been fitted to the data to determine the energy calibration as well as the linearity of the calibration curve. 


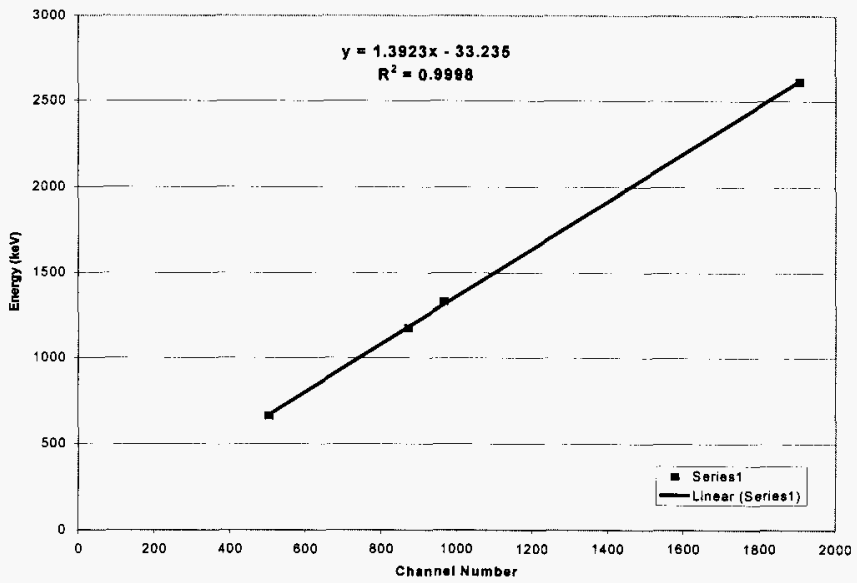

Figure 8 - Energy Calibration of Gamma Spectroscopy Sensor performed on 8/23/98.

\subsubsection{Gamma and XRF Module - Gamma Throughput Test}

PURPOSE:

Demonstrate the throughput capability of the Gamma Sensor $(5.1 .12)$

\section{EQUIPMENT CONDITIONS:}

The MSP \#1 was laid horizontal on a benchtop. The gamma check source holder with the calibration sources in place was centered on the $\mathrm{Nal}$ crystal. The three sources in the holder were a $1 \mu \mathrm{Ci} \mathrm{Cs}-137$ (488-34-6), a $1 \mu \mathrm{Ci} \mathrm{Co-60} \mathrm{source} \mathrm{(1U511)} \mathrm{and} \mathrm{a} 0.1 \mu \mathrm{Ci}$ Th-288 (43393-2). The Cs source was aligned axially with the XRF window. The MSP\#1 probe was connected through the umbilical cable to the electronics that are part of the total system. The electronics were set a described below.

Gamma Electronics

High Voltage: 630 volts

Coarse gain: 20

Fine Gain: 1.18

Shaping Time: $1 \mu \mathrm{sec}$

BLR : Auto
XRF Electronics EG\&G 671 Amp Coarse Gain: 5 Fine Gain: 0.5 Shaping Tim $6 \mu \mathrm{sec}$ BLR : PZ 
Shaping :

Gaussian

Shaping :

Gaussian

AmpTek Gain:

1.18

AmpTek RTD:

Off

TEST DATE:

$8 / 23 / 98$

TEST:

A series of spectra were collected using a variety of sources to increase the count rates to determine the throughput of the gamma spectroscopy system. Table 2 below presents the count rates, sources and files names. Each spectrum was counted for 300 seconds of live time.

\section{EXPECTED:}

Less than $5 \%$ loss in resolution and $<0.1 \%$ gain shift.

TEST RESULT(S):

Table 2 below presents a summary of the important information from each of the three spectrums that were collected. Figure 9 presents an overlay of the three spectrums that were collected.

Table 2- Throughput summary information

\begin{tabular}{|c|c|c|c|c|c|c|c|}
\hline \multirow[b]{2}{*}{ Filename } & \multirow[b]{2}{*}{ cts/sec } & \multirow[b]{2}{*}{\begin{tabular}{|l|} 
Dead \\
Time
\end{tabular}} & \multirow[b]{2}{*}{ Cs Res } & \multicolumn{4}{|c|}{ Gain Shifts } \\
\hline & & & & Cs & $\mathrm{Co-1}_{0}$ & Co-2 & Th \\
\hline $\begin{array}{l}3 \text { Cal01 } \\
3 \text { cal } 02 \\
3 \text { Cal03 }\end{array}$ & $\begin{array}{l}3500 \\
10000 \\
20000\end{array}$ & $\begin{array}{l}7.23 \% \\
23.30 \% \\
54.91 \%\end{array}$ & $\begin{array}{l}7.56 \% \\
7.57 \% \\
7.73 \%\end{array}$ & $\begin{array}{l}0.01 \% \\
-0.26 \% \\
1.12 \%\end{array}$ & $\begin{array}{l}0.03 \% \\
0.30 \% \\
1.51 \%\end{array}$ & $\begin{array}{l}0.11 \% \\
1.78 \% \\
3.50 \%\end{array}$ & $\begin{array}{l}0.00 \% \\
-0.55 \% \\
0.56 \%\end{array}$ \\
\hline
\end{tabular}

Notes 1) 3Cal01 - used check standard sources

2) 3 Cal02 - used check sources and a Na22 source

3) 3Cal03 - used check sources, $\mathrm{Na} 22$ and $10 \mu \mathrm{Ci} \mathrm{Ba} 133$ 


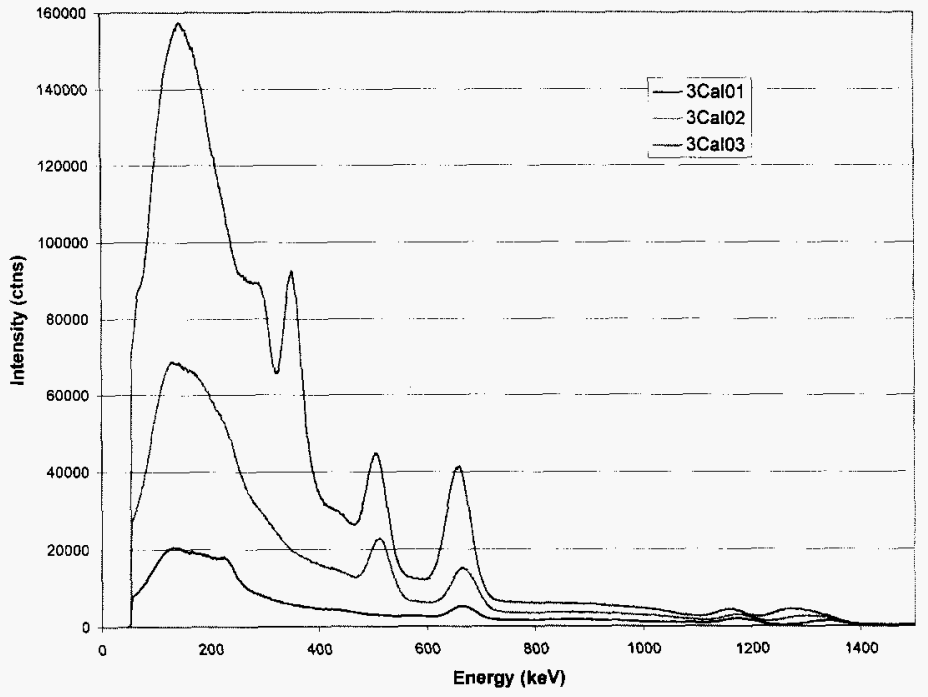

Figure 9 - Spectrums from the throughput tests

The test results indicate that the performance of the $\mathrm{Nal}$ crystal in terms of resolution does not diminish significantly as the count rate increases to $20,000 \mathrm{cnts} / \mathrm{sec}$. The Cs resolution drops by less than $0.2 \%$ as the dead time increases from 7 to 54 percent. A gain shift in all the peaks is noted however. The temperature of the probe was not noted so it is impossible determine the portion of the gain shift due to temperature and that due to count rate. For most peaks, the total gain shift is less than $2 \%$.

Table 3 below presents the net area under the two cobalt peaks for each of the three spectra. For the first peak, the counts are constant which would be expected as additional activity in the cobalt region has not been added. The second cobalt peak however shows a significant increase when the $\mathrm{Na22}$ was added. The increase occurs again, but not as significantly when the Ba133 is added. 
Table 3 - Net Areas of the Co-60 peaks for Throughput Test

\begin{tabular}{|l|c|c|c|c|}
\cline { 5 - 5 } \multicolumn{2}{c|}{ Filename } & cts/sec & Dead & Not Areas \\
\hline & & Time & & Co-2 \\
\hline 3Cal01 & 3500 & $7.23 \%$ & 65759 & 62935 \\
3cal 02 & 10000 & $23.30 \%$ & 59298 & 122198 \\
3Cal03 & 20000 & $54.91 \%$ & 70178 & 176145 \\
\hline
\end{tabular}

\subsubsection{Gamma Module-Efficiency Testing}

\section{PURPOSE:}

Document the efficiency of the Nal crystal (5.1.8 \& 5.1.9).

\section{EQUIPMENT CONDITIONS:}

The MSP \#1 was laid horizontal on a benchtop. The gamma check source holder with the calibration sources in place was centered on the Nal crystal. The three sources in the holder were a $1 \mu \mathrm{Ci} \mathrm{Cs}-137$ (488-34-6), a $1 \mu \mathrm{Ci} \mathrm{Co-60} \mathrm{source} \mathrm{(1U511)} \mathrm{and} \mathrm{a} 0.1 \mu \mathrm{Ci}$ Th-288 (43393-2). The Cs source was aligned axially with the XRF window. The MSP\#1 probe was connected through the umbilical cable to the electronics that are part of the total system. The electronics were set a described below.

Gamma Electronics

High Voltage: 630 volts

Coarse gain: 20

Fine Gain: 1.18

Shaping Time: $1 \mu \mathrm{sec}$

Shaping Time: $6 \mu \mathrm{sec}$

BLR : Auto

Shaping :

Shaping :

AmpTek Gain:

AmpTek RTD:
XRF Electronics

EG\&G 671 Amp

Coarse Gain: 5

Fine Gain: $\quad 0.5$

BLR : PZ

Gaussian

Gaussian

1.18

Off

TEST DATE:

8/23/98 
TEST:

A 300-second spectrum was collected with the sources in place. The check sources were then removed and a $10 \mu \mathrm{Ci}$ Cs- 137 source (birthdate $8 / 1 / 93$ at $10.35 \mu \mathrm{Ci}$ ) was placed 10 inched from the centerline of detector at the midpoint. A second spectrum was collected

EXPECTED:

A constant efficiency between the two tests considering the geometry effects.

TEST RESULT(S):

The spectrum for the check sources was collected using the Maestro Software and is stored in File 3cal01. Figure 7 presents the plotted spectrum. The table below presents the ROI report from Maestro. Efficiencies are calculated and shown in Table 4.

Table 4 - Gamma Detector efficiency for the check sources in the check source holder.

Detector \#1 ACQ 23-Aug-1998 at 9:51:47 RT = 965.1 LT $=900.0$ MSPDAS MCB 1

\begin{tabular}{|r|r|r|r|r|r|r|r|r|} 
ROI\# & RANGE & $(\mathrm{keV})$ & GROS & NET & $+/-$ & $\begin{array}{c}\text { Activity } \\
(\mu \mathrm{Ci})\end{array}$ & $\begin{array}{c}\text { Eff. } \\
(\mathrm{cnts} / \mathrm{s} / \mu \\
\mathrm{Ci})\end{array}$ \\
\hline 1 & Cs & 608.44 & 733 & 317389 & 116571 & 1740 & 0.9703 & 133.4 \\
\hline 2 & Co & 1103.78 & 1239.67 & 128642 & 65759 & 1025 & 0.9155 & 79.80 \\
\hline 3 & Co & 1263.06 & 1409.2 & 89614 & 62935 & 715 & 0.9155 & 76.02 \\
\hline 4 & Th & 2510.75 & 2708.83 & 3310 & 1840 & 186 & 0.1670 & 22.02 \\
\hline
\end{tabular}

The spectrum for the $10 \mu \mathrm{Ci}$ Cs-137 source was also collected using the Maestro Software and is stored in File CScal01. Figure 9 presents the plotted spectrum. The table below presents the ROI report from Maestro. Efficiencies are calculated and shown in Table 5. A geometry factor of $1 / r^{2}$ has to be incorporated into the calculations to account for the different test configurations so the values can be compared. Based upon the geometry factor and the efficiency measured using the sample holder, the efficiency at 10 inches should be $3.00 \mathrm{cnts} / \mathrm{sec} / \mu \mathrm{Ci}$ (using 1.5-inch radius for the sample holder). This value compares favorably to $3.5 \mathrm{cnts} / \mathrm{sec} / \mu \mathrm{Ci}$ presented in Table 5. 


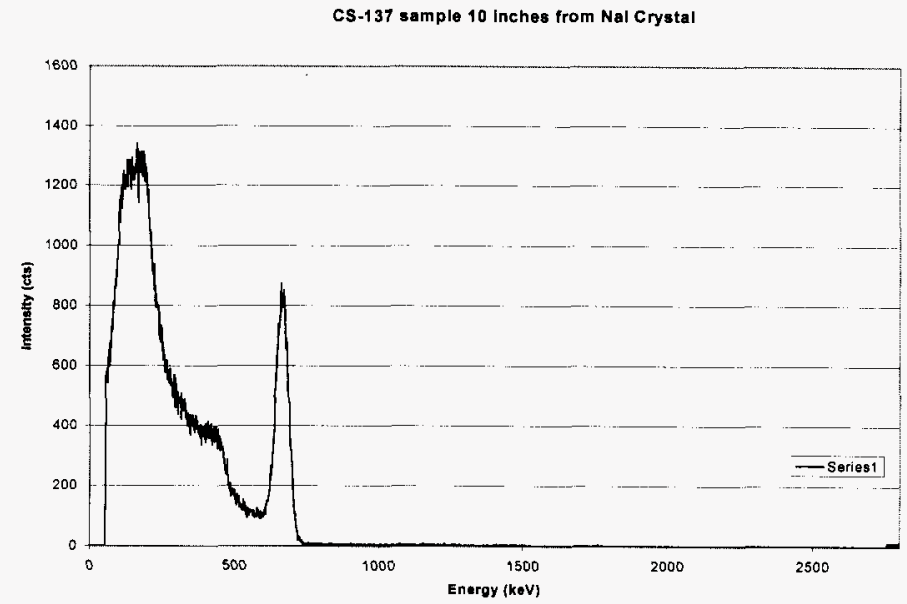

Figure 10 - Spectrums from the $10 \mu \mathrm{Ci} \mathrm{Cs}-137$ source at 10 inches from $\mathrm{Nal}$ Crystal centerline.

Table 5 - Check Standard Gamma measurements from file CSCal01.chn

Detector \# - ACQ 23-Aug-1998 at 11:25:17 RT $=904.0$ LT $=900.0$ MSPDAS MCB 1

\begin{tabular}{|c|c|c|c|c|c|c|c|}
\hline ROI\# & RANGE & (keV) & GROS & NET| & $+1-$ & $\begin{array}{l}\text { Activity } \\
(\mu \mathrm{Ci})\end{array}$ & $\begin{array}{l}\text { Eff. } \\
\text { (cnt/s/ } / \mu \\
\text { Ci) }\end{array}$ \\
\hline & 573.32 & 723.51 & 36306 & 30351 & 368 & 9.482 & 3.556 \\
\hline
\end{tabular}




\subsubsection{Gamma \& XRF Module - Hanford Soil matrix sample Testing}

PURPOSE:

Determine the minimum detection limit for the gamma sensor (5.1.5). For the XRF sensor, testing was conducted to ensure proper operation in a radiation field similar to that expected in the field.

EQUIPMENT CONDITIONS:

The MSP \#1 was laid horizontal on a benchtop and a background measurement was made. The probe was then inserted into the inner two-inch PVC tube of the sample test chamber. The MSP\#1 probe was connected through the umbilical cable to the electronics that are part of the total system. The electronics were set a described below.

$\begin{array}{ll}\text { Gamma Electronics } & \text { XRF Electronics } \\ \text { High Voltage: } 630 \text { volts } & \text { EG\&G } 671 \text { Amp } \\ \text { Coarse gain: } 20 & \text { Coarse Gain:5 } \\ \text { Fine Gain: } 0.975 & \text { Fine Gain: } 0.5 \\ \text { Shaping Time: } 1 \mu \mathrm{sec} & \\ \text { Shaping Time: } 6 \mu \mathrm{sec} & \\ \text { BLR: Auto } & \text { BLR : PZ } \\ \text { Shaping : } & \text { Gaussian } \\ \text { Shaping : } & \text { Gaussian } \\ \text { AmpTek Gain: } & 1.18 \\ \text { AmpTek RTD: } & \text { Off }\end{array}$

\section{TEST DATE:}

$8 / 25 / 98$

\section{TEST:}

A test sample was constructed in an 18-inch diameter PVC pipe that was 36 inches long. A 2-inch PVC pipe was installed in the center of the two end caps for the probe to be inserted through. The sample was filled in three roughly equal lifts with Hanford soil material moistened with water and a mixture of Cs-137 and Co-60. The water and contaminates were mixed in a slightly acidic solution such that the moisture content would be approximately 5 percent, the $C s$ would be approximately $200 \mathrm{pCi} / \mathrm{gm}$ and the Co-60 would be approximately 200 $\mathrm{pCi} / \mathrm{gm}$. The liquid mixture was mixed in a concrete mixer with dry Hanford soil until a uniform mixture was obtained (approximately 7-10 minutes). The soil was then loaded into the test chamber. Each batch 
used approximately $154 \mathrm{lbs}$ of dry soil and $1 / 3$ of the solution. The total sample weighs approximately $450 \mathrm{lbs}$. Three soil samples were taken from each lift at roughly 120-degree positions. These samples were tested by the NCSU laboratory to determine the actual activity value for each lift. The three values for each lift were averaged for analysis purposes. (Analysis of the sample results provided by NDSU indicates that sample \#2 and sample \#5 appear to have been switched. This was determined since the results from sample \#2 are more similar to the other results from he middle layer than the bottom layer. The same is true for sample \#5 except it matches better with the bottom layer than the middle layer. )

Measurements were made using the MSP at 9-inch intervals over the entire length of the sample. The 0 position was defined as the lower Gamma module joint flush with the "bottom" of the test sample. (The sample was laid on its side for testing, but was built in a vertical orientation and the bottom refers to the bottom of the sample.) Three measurements were made at each position at rotational portions of 0 , 120 and 240 degrees. The gamma temperature was read off a DVM prior to each measurement and entered into the MSP-DAS system so the resulting files are temperature corrected. Collections times were 300 second for both the gamma and XRF measurements.

\section{EXPECTED:}

A collection of spectrums that show the ability of the $\mathrm{Nal}$ sensor to detect CS-37 and Co-60 contamination in a Hanford soil matrix as well as calculate the minimum detection limit for the gamma sensor. Proper operation of the XRF in the sample radiation field is expected.

TEST RESULT(S):

All spectra for these tests were collected using MSP-DAS v 1.0 software. The gamma files were saved in files "Z0959601G002-0D" through Z0959601G002-0S. The XRF files are in "Z0959601X002OD" through "Z0959601X002-OS". To simplify the analysis all of the gamma spectra at a single position were averaged together to determine the results for that position. It should be noted that for positions 0 and 36 inches, the gamma sensor is not within the test sample. Figure 11 presents an overlay plot of the gamma spectra at each position. As expected the three spectra within the sample are very similar, while the two outside the sample have reduced counts. In addition to the reduced count, there is also a slight gain shift in the spectrum at the 0 position. This shift was not temperature related and needs to be investigated further to determine its cause. For all other 
spectra, the temperature conversion took care of any gain shifts related to temperature.

\section{Hanford Soil Matrix Sample}

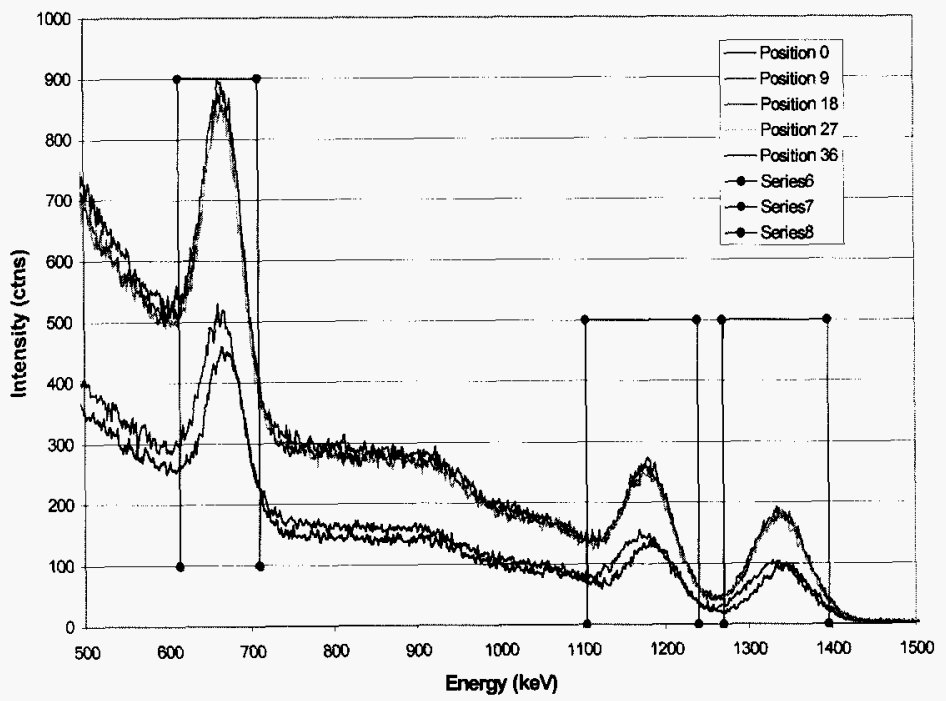

Figure 11 - Hanford Soil Matrix Spectra at various positions along sample

Also shown in Figure 11 are the boundary lines of the regions of interest used to determine the area associated with each peak. A gross and net area was determined for each peak. The background area was determined using a trapezoidal approach. Table 6 presents the area for each peak. These areas are compared to the average activity for each of the three lifts of the sample in Figure 12. In general, the same trends shown in the spectra measured using the MSP are shown in the laboratory results from the soil samples. Using the area 
values the minimum detection limits for Cs-137 can be calculated using Equation 1 for each layer. The results from these calculations were $11.04,12.41,11.55 \mathrm{pCi} / \mathrm{gm}$ for the positions 9,18 and 27 respectively. The average was $11.66 \mathrm{pCi} / \mathrm{gm}$. This does not meet the goal of $10 \mathrm{pCi} / \mathrm{gm}$, however it is close.

$$
M D L=4.66 * \frac{\sqrt{\text { Background Counts }}}{\text { Counts }} * \frac{p C i}{g m}
$$

Eq. 1

Table 6 - Summary of Area from the Hanford Soil Matrix Testing

\begin{tabular}{|r|r|r|r|r|r|r|}
\hline & \multicolumn{3}{|c|}{ Gross Area } & \multicolumn{3}{|c|}{ Net Area } \\
\cline { 2 - 8 } Position & CS Area & Co (1173) & Co(1333) & CS Area & Co (1173) & Co(1333) \\
\hline 8ackground & 1523 & 665 & 395 & & & 3935 \\
0 & 24325 & 8807 & 5439 & 7801 & 3582 \\
9 & 46757 & 16933 & 10526 & 16063 & 6890 & 6496 \\
18 & 48159 & 17392 & 10878 & 15368 & 8267 & 7196 \\
27 & 45644 & 16520 & 10265 & 14774 & 7931 & 6476 \\
36 & 27493 & 9890 & 6083 & 9115 & 4279 & 3789 \\
\hline
\end{tabular}

Hanford Soll Matrix Sample

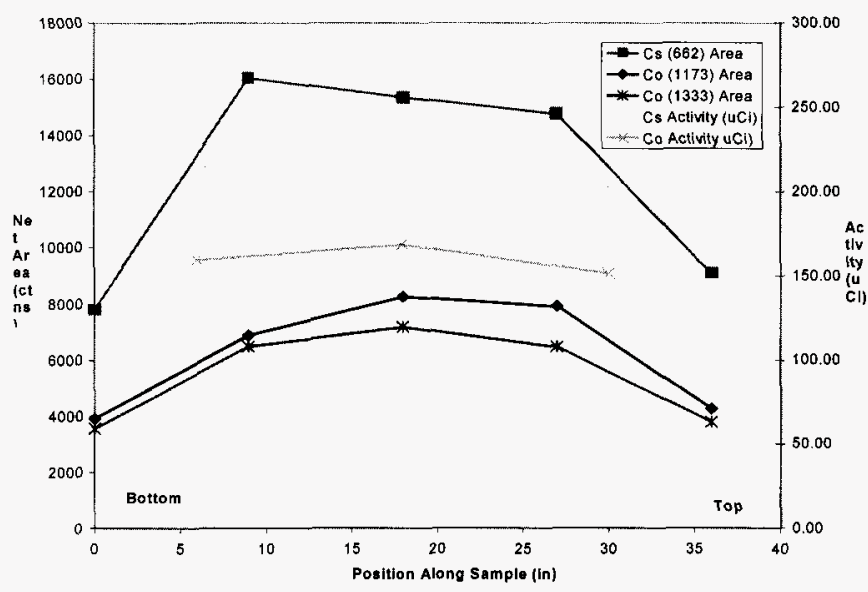

Figure 12 - Activity comparisons of the Hanford Soil Matrix Sample 


\subsection{Soil Sampler Probe Development Tests}

\subsubsection{Soil Sampler Probe - Latching Mechanism}

PURPOSE:

Demonstrate the operation of the modified upper latching mechanism. The latching mechanism secures and releases the Magnetometer/Inclinometer unit or a sample chamber in to and out of the SSP outer housing.

EQUIPMENT CONDITIONS:

The SSP was assembled with the $M / I$ unit and pushed to the bottom of an existing 25 ' hole. (The sample chamber has no tip. The M/I unit MUST be used when pushing.)

TEST DATE:

\section{$10 / 7 / 98$}

TEST:

The test was conducted at the ILAW site of the Hanford facility. The SSP was pushed to the bottom of a 25' hole. The M/I unit was released with a tug on the inner rods and brought to the surface. A sample chamber was lowered and latched into its place. The SSP was pushed 8 inches to fill the chamber. The sample chamber was release and brought to the surface. The $M / I$ unit was lowered and latched into the outer housing and SSP was pushed $1 \mathrm{~m}$ (one rod length). The procedure was repeated four times for a total of five samples.

\section{EXPECTED:}

The latching mechanism should easily and repeatedly latch and unlatch, securing the $M / /$ unit or a sample chamber in the outer housing. The latch should hold for a push force of greater than 45,000 lbs.

TEST RESULT(S):

The latched worked as expected. It easily unlatched with a few tugs on the inner rods. It latched easily with each try. It allowed the operator to "feel" when it was latched by the amount of play in the inner rods once latched. The latch held with push 
pressures of greater than $45 \mathrm{Klbs}$. See Attachment 4 for complete testing information.

\subsubsection{Soil Sampler Probe - Inclinometer Sensor}

PURPOSE:

Demonstrate presence of a two-axis inclinometer sensor, which measures angle of deflection off vertical in both an $X$ and $Y$ direction. The sensor shall have a reading range of $\pm 15^{\circ}$ with a linearity of $0.5 \%$.

EQUIPMENT CONDITIONS:

The SSP was calibrated by the vendor using the MSP inclinometer calibration procedure. The calibration was then verified using the inclinometer verification jig and a "smart level" brand digital level. The smart level was checked using a set of reference angle blocks.

TEST DATE:

$10 / 23 / 98$

TEST:

The test was conducted at the ILAW site of the Hanford facility. The probe was placed in the inclinometer calibration jig at an approximate angle of 10 degrees. The CPP_DAS software was started. Using the monitor channel option of the code, the probe was slowly rotated until the maximum value for the $x$-axis inclination was determined. The probe was then locked into the jig. The probe was positioned vertically in the jig. Using the verification section of the CPP-DAS code, baseline readings were taken. The probe was then inclined to an approximate 15degree angle. The space bar was pushed and the reading from the smart level (reference gage) entered. The procedure was repeated for the $y$-axis verification.

EXPECTED:

The inclination recorded by the MSP probe must compare within $2 \%$ of the value from the reference gage.

TEST RESULT(S):

Both the $\mathrm{X}$-axis and $\mathrm{Y}$-axis calibration plots are attached along with the printed verification test pages (Attachment 4). The 
results of the verification are also presented in the following table.

$\begin{array}{lll} & \text { X Axis } & \text { Y Axis } \\ \text { SSP Probe readings } & 17.59^{\circ} & 16.21^{\circ} \\ \text { Reference Gage } & 17.7^{\circ} & 16.5^{\circ} \\ \text { Percent Difference } & 0.62 \% & 1.73 \%\end{array}$

\subsubsection{Soil Sampler Probe - Magnetometer Sensor}

\section{PURPOSE:}

Demonstrate the operation of the magnetometer that detects the presence of ferrous material in the vicinity of the tip of the SSP.

EQUIPMENT CONDITIONS:

The SSP magnetometer was calibrated by the vendor using the MSP inclinometer calibration procedure. The SSP was assembled with the M/I unit. Using the CPP, it was lower to the ground surface beneath the platform. The target plate was placed directly beneath the tip on the ground.

TEST DATE:

$10 / 23 / 98$

TEST:

The test was conducted at the ILAW site of the Hanford facility. The tip of the SSP was position 6"above the target plate. Using the CPP DAS verification procedure, baseline readings were recorded. The probe was lowered to 2" above the target plate. The verification was confirmed and the measured distance between the probe tip and the target plate using a tape measure was entered.

\section{EXPECTED:}

The magnetometer should display the distance in inches between the tip and the target plate.

TEST RESULT(S):

The magnetometer operated as expected. The verification sheet and calibration curve are shown in Attachment 4. 


\section{SSP Probe readings $\quad 2.028$ inches \\ Reference Gage Percent Difference 2.0 inches \\ $0.18 \%$}




\begin{tabular}{|c|c|c|c|c|}
\hline Tip Load Ce & Calibration Data Sheet & \multicolumn{2}{|c|}{ Ref Load Cell \# $76197 \mathrm{~A}$} & \\
\hline Data Point Number & Tip Load & Reference Load & Reference Load & \\
\hline & (volts) & (volts) & (lbs) & \\
\hline 1 & & & & \\
\hline 2 & & & & \\
\hline 3 & & & & \\
\hline 4 & & & & \\
\hline 5 & & & & \\
\hline 6 & & $8)(1015$ & & \\
\hline 7 & & 4.0 & & \\
\hline 8 & $6 e^{2}$ & $x^{\circ}+186^{\circ}$ & & \\
\hline 9 & & ile & & \\
\hline 10 & & $x^{\prime}$ & & \\
\hline 11 & & & & \\
\hline 12 & & & & \\
\hline 13 & & & & \\
\hline 14 & & & & \\
\hline 15 & & & & \\
\hline 16 & Validation Test & Data & & \\
\hline 17 & Tip Lond (Ibs) & Meferense Loul (16) & $\%$ difference & \\
\hline 18 & 10450 & 10460 & .096 & $<2 \%$ ok \\
\hline 19 & 10,400 & 10370 & 0.289 & $\angle 2 \%$ ok \\
\hline 20 & 8644 & 8678 & 0.392 & $\angle 2 \%$ ok \\
\hline
\end{tabular}

Use a analysis software package such as Microsoft Excel or DPlot to develop a first order curve fit for the tip load cell data in volts and the reference load cell data in lbs.

First order Curve Fit: $\quad x=3.667 E-02 \mathrm{y} \quad(3.667 \mathrm{E}-02 \mathrm{mv} / \mathrm{bb})$

Sensor/Probe Number or Name:__ MSP1

Performed By/ Witnessed By:

WLB/SMT WSC $(8 / 19 / 78)$ WSC

Date

WeB/ARA

Initials/Org. 

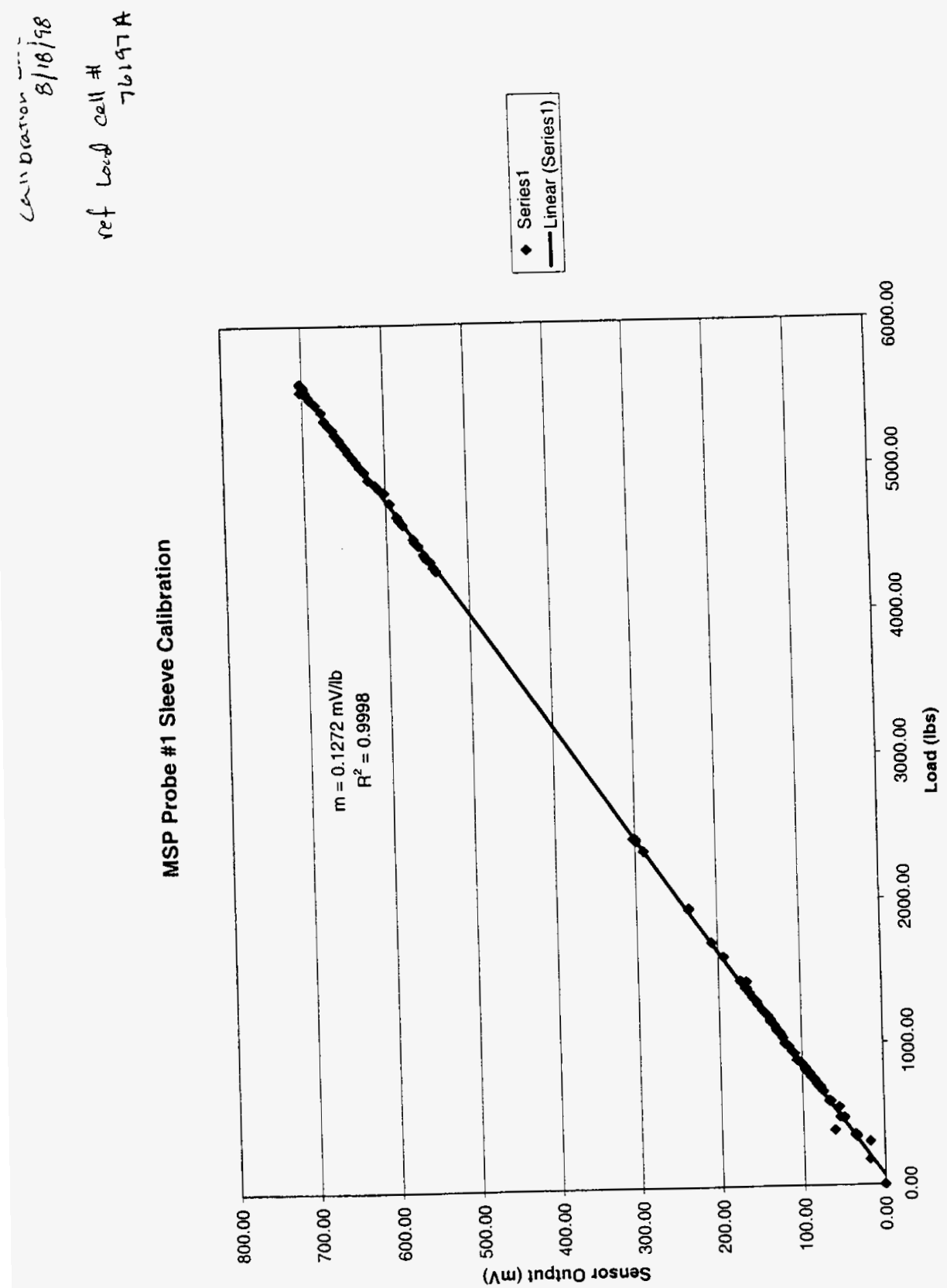

$40 / 72$ 
6.3) Sleeve Load Cell Calibration Data Sheet

Ref Load Cell \# $76197 A$

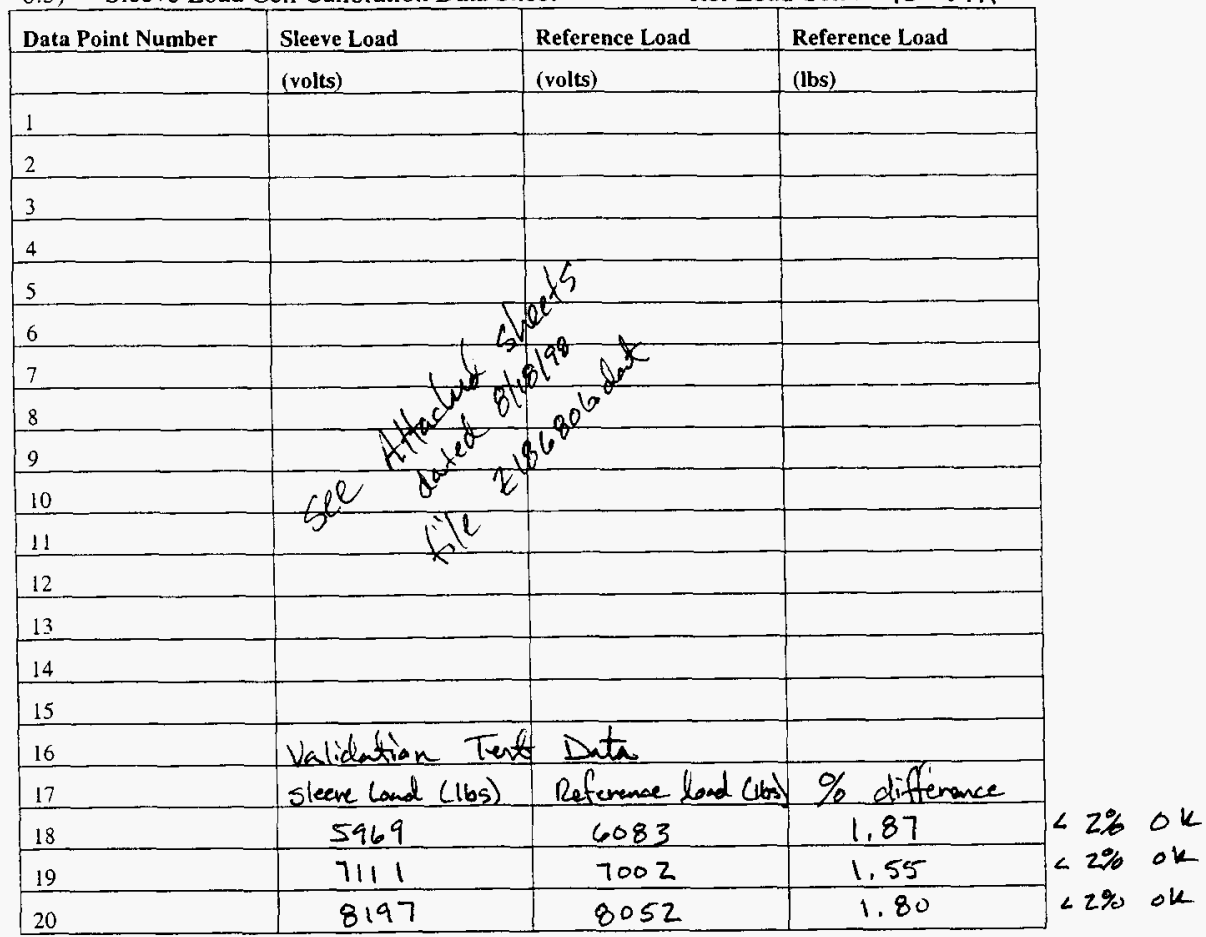

Use a analysis software package such as Microsoft Excel or DPlot to develop a first order curve fit for the sleeve load cell data in volts and the reference load cell data in lbs..

First order Curve Fit? $y=1272 x \quad(0.1272 \mathrm{mv} / \mathrm{ib})$

Sensor/Probe Number or Name: MSPI

Performed By/ Witnessed By:

$\frac{W L B / S M T}{\text { Date }} \quad$ WSC $(8 / 18 / 98) \omega S C$

$W C B / A R A$

Initials/Org. 


\section{VERTEK}

RR 1, Box 120A, Waterman Road

South Royalton, Vermont 05068

phone: (800) 639-6315 fax: (802) 763-8283

Manufacturer

Model

Load Cell S/N

Rated Range

Calibrated with:

Excitation

Amplification

Load Reference:

\begin{tabular}{|c|c|}
\hline $\begin{array}{l}\text { Load } \\
\text { (ID) }\end{array}$ & $\begin{array}{l}\text { Net Output } \\
\text { (mv) }\end{array}$ \\
\hline 0 & 0.0000 \\
\hline 1000 & -2.0907 \\
\hline 2000 & -4.1789 \\
\hline 3000 & -6.2692 \\
\hline 4000 & -8.3582 \\
\hline 5000 & -10.4460 \\
\hline 6000 & -12.5347 \\
\hline 7000 & -14.6239 \\
\hline 8000 & -16.7124 \\
\hline 9000 & -18.8027 \\
\hline 10000 & -20.8902 \\
\hline 9000 & -18.8007 \\
\hline 8000 & -16.7123 \\
\hline 7000 & -14.6246 \\
\hline 6000 & -12.5359 \\
\hline 5000 & -10.4462 \\
\hline 4000 & -8.3571 \\
\hline 3000 & -6.2699 \\
\hline 2000 & -4.1800 \\
\hline 1000 & -2.0898 \\
\hline 0 & .0 .0023 \\
\hline
\end{tabular}

Sensitivity

Cal. Factor

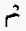

Nonlinearity

Zero Load Output
Interface

1211NE-10K

76197A .REF

$10000 \mathrm{tb}$

\subsection{Volt DC}

1.0000

Interface S/N72693A

\section{Reference Load Cell Calibration}

EF

of
Date:

Calibrated by:

Approved by:

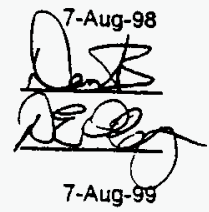

Date Due:

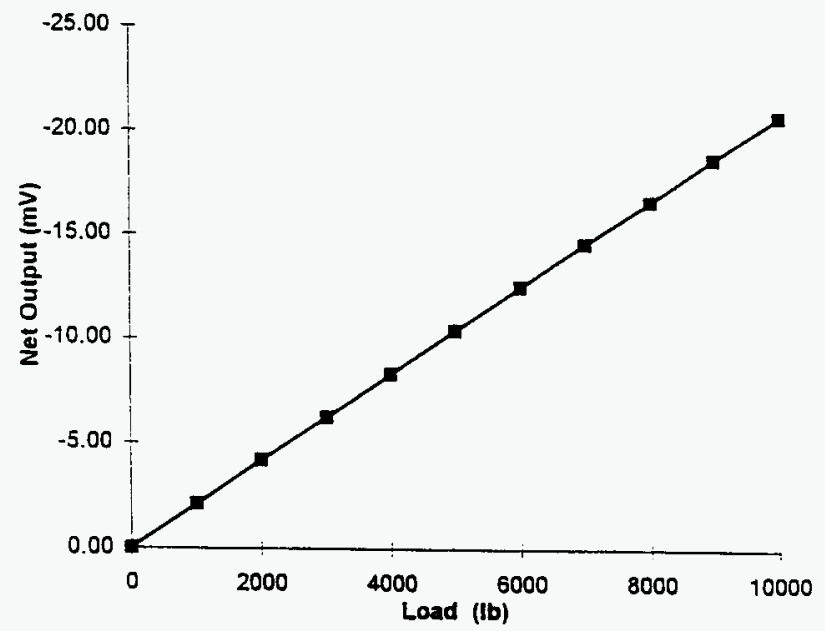

-4.177E-04 mV/V/lb

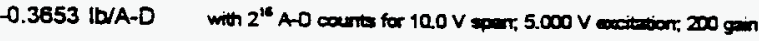
1.000000

-0.01\% calibrated range

$-0.0247 \mathrm{mVN}$ 


\section{VerTEK}

RR 1. Box 120A Watermon Rocd

South Royalton, Vermont 05068

phone: (800) 639-6315 fox: (802) 763-8283

Relerence Load Cell Callbration

$\begin{array}{lc}\text { Manufacturer } & \begin{array}{c}\text { Interface } \\ \text { Model }\end{array} \\ \text { Load Cell S/N } & 726930-10 \mathrm{~K}-\mathrm{B} \\ \text { Roted Range } & 10000 \mathrm{lb} \\ \text { Calibrated with: } & \\ \text { Excitation } & 5.00025 \text { Volt DC } \\ \text { Amplification } & 1.0000 \\ \text { Lood Reference: } & \text { Proving Ring S/N } 13193\end{array}$

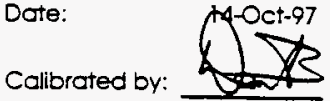

Approved by:

\begin{tabular}{|c|c|}
\hline $\begin{array}{c}\text { Load } \\
\text { (ib) }\end{array}$ & $\begin{array}{c}\text { Net Output } \\
\text { (mV) }\end{array}$ \\
\hline 0 & 0.0000 \\
\hline 1245 & -2.4400 \\
\hline 2224 & -4.4740 \\
\hline 3203 & -6.5250 \\
\hline 4181 & -8.5930 \\
\hline 5160 & -10.6900 \\
\hline 6138 & -12.7810 \\
\hline 7116 & -14.7890 \\
\hline 8093 & -16.8260 \\
\hline 9070 & -18.9500 \\
\hline 10047 & .20 .9910 \\
\hline & \\
\hline & \\
\hline & \\
\hline & \\
\hline & \\
\hline & \\
\hline & \\
\hline & \\
\hline & \\
\hline
\end{tabular}

Sensitivity

$r^{2}$

Nonlinearity

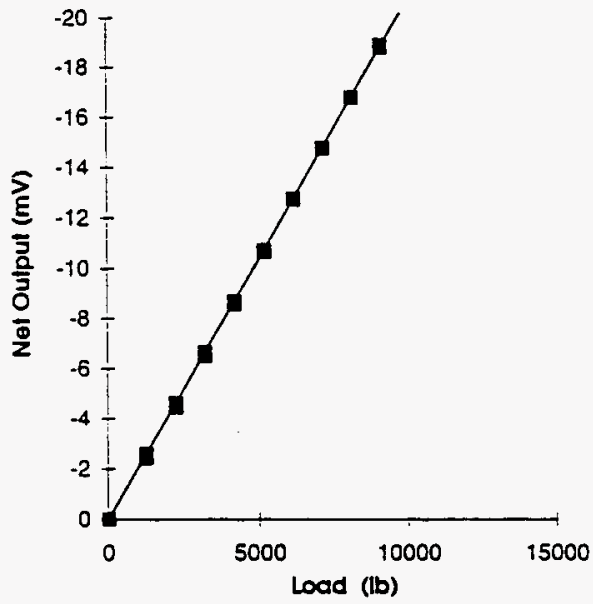

$-4.1991 \mathrm{mV} / \mathrm{VFSO}$

0.999927

$-0.72 \%$ callbrated range 
National Standards

P.O. Box 5808

15753 Crabbs Branch Way

Rockville, Maryland 20855

Lab No. SJT.01/106813

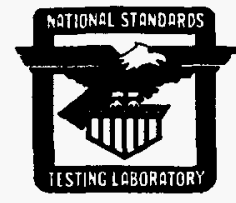

Trans Letter 7-7-97
$301-590-0097$

\section{Testing Laboratory}

Order No. 5324

\title{
Certificate
}

\author{
Steel City Optical Proving Ring No. 13193 \\ submitted by \\ Applied Research Associates, Inc. \\ South Royalton, Vermont
}

Steel City Optical Proving Ring No. 13193, capacity 120,000 lbf compression, was calibrated to $112,000 \mathrm{lbf}$ compression in accordance with ASTM specification E 74-95, "Standard Practice of Calibration of Force-Measuring Instruments for Verifying the Force Indication of Testing Machines." The calibration complies with the requirements of ISO 10012-1, ANSINCSL Z5401, MIL-STD-45662A, and 10CFR Part 21. The calibration was performed using a combination of transfer standards calibrated by the National Institute of Standards and Technology (NBS) under Lab Nos. 258466 and 257044. The errors of the applied loads did not exceed 0.01 percent. The calibration of the device was completed on August 27, 1997.

The deflection values given in the summary table and the values of the computed loads given in the calibration table are correct for a temperature of 23 degrees Celsius. If the device is used at a different temperature of $t^{\circ} \mathrm{C}$, the observed deflections should be corrected to $23^{\circ} \mathrm{C}$ by the multiplying factor

$$
f=1-(t-23)(0.00027)
$$

The results of the calibration, including statistical analysis of calibration data in accordance with ASTM E 74-95, are given in Table 1. Computed load versus deflection tables are also attached. As prescribed by Section 11 of ASTM E 74-95, this device should be recalibrated on or before August 27, 1999.

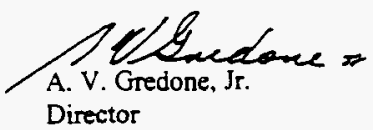

Atrachments: load and summary tables 

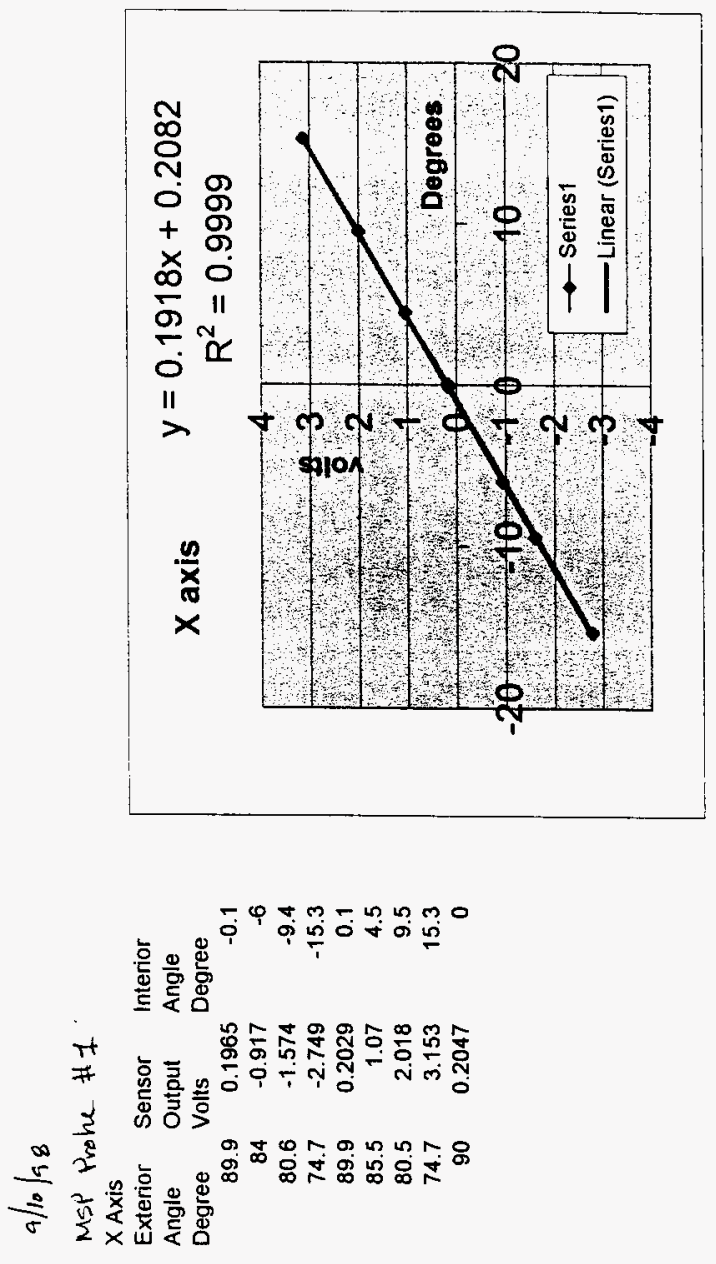


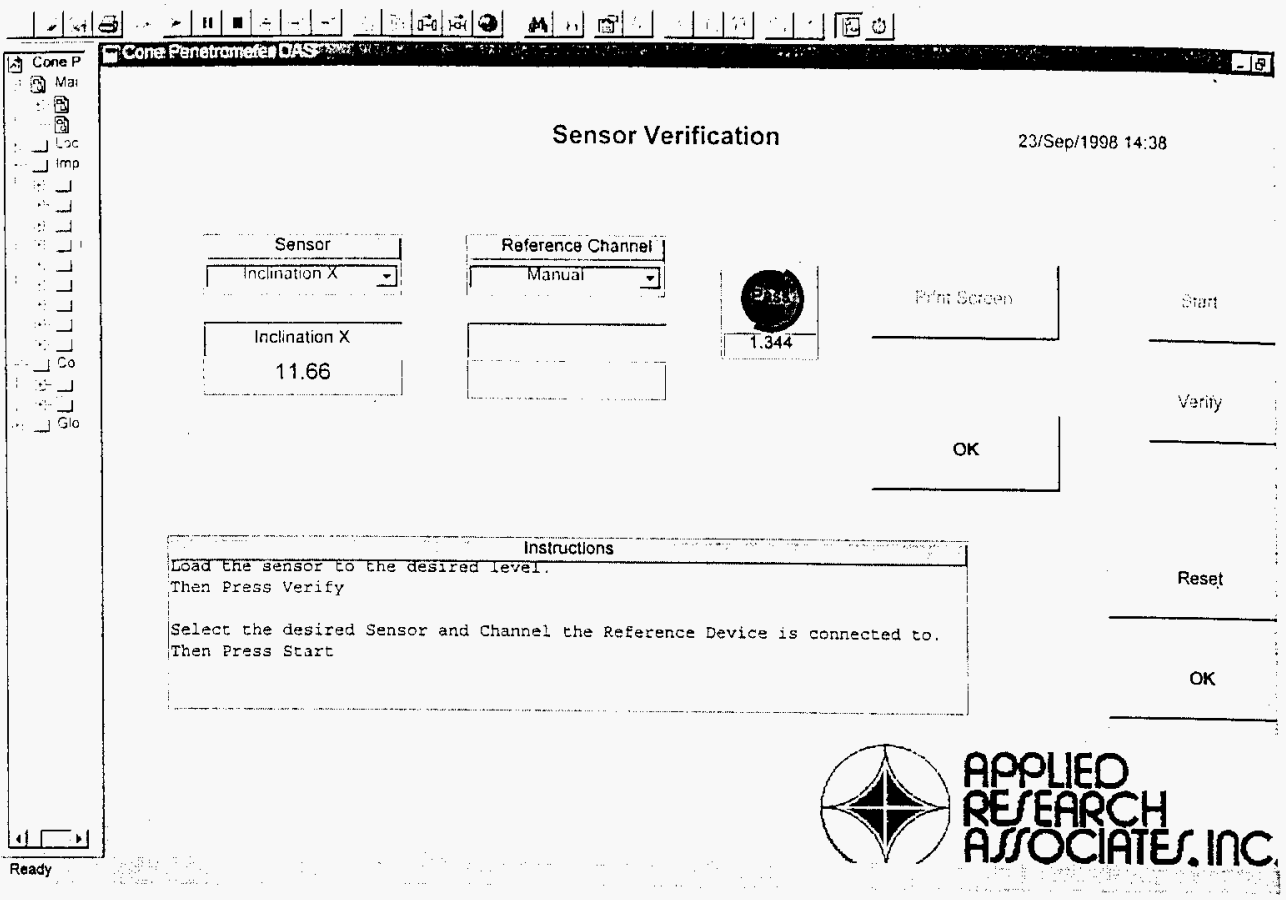




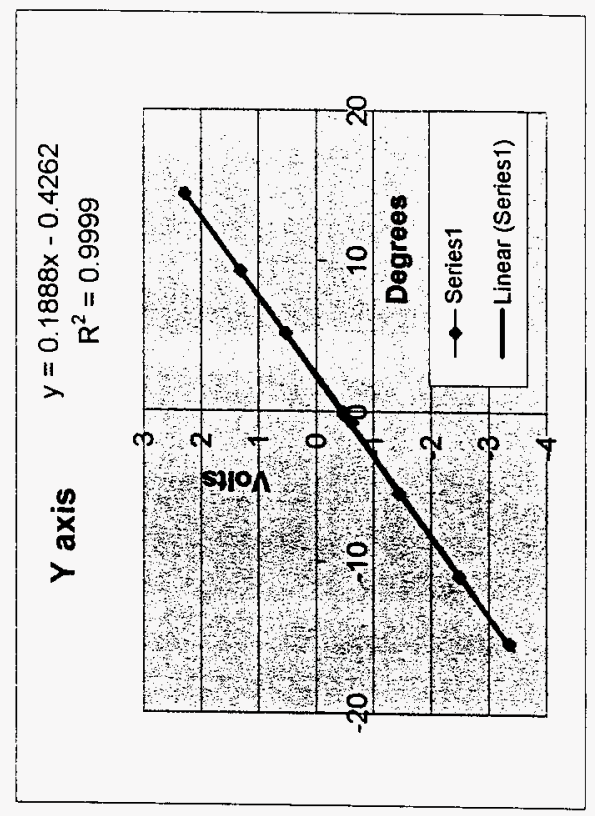

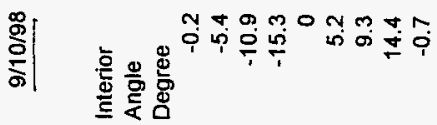

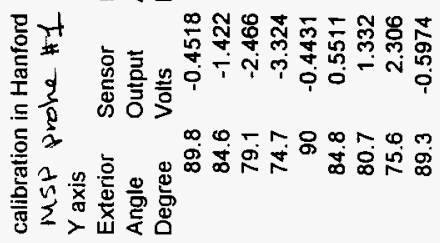




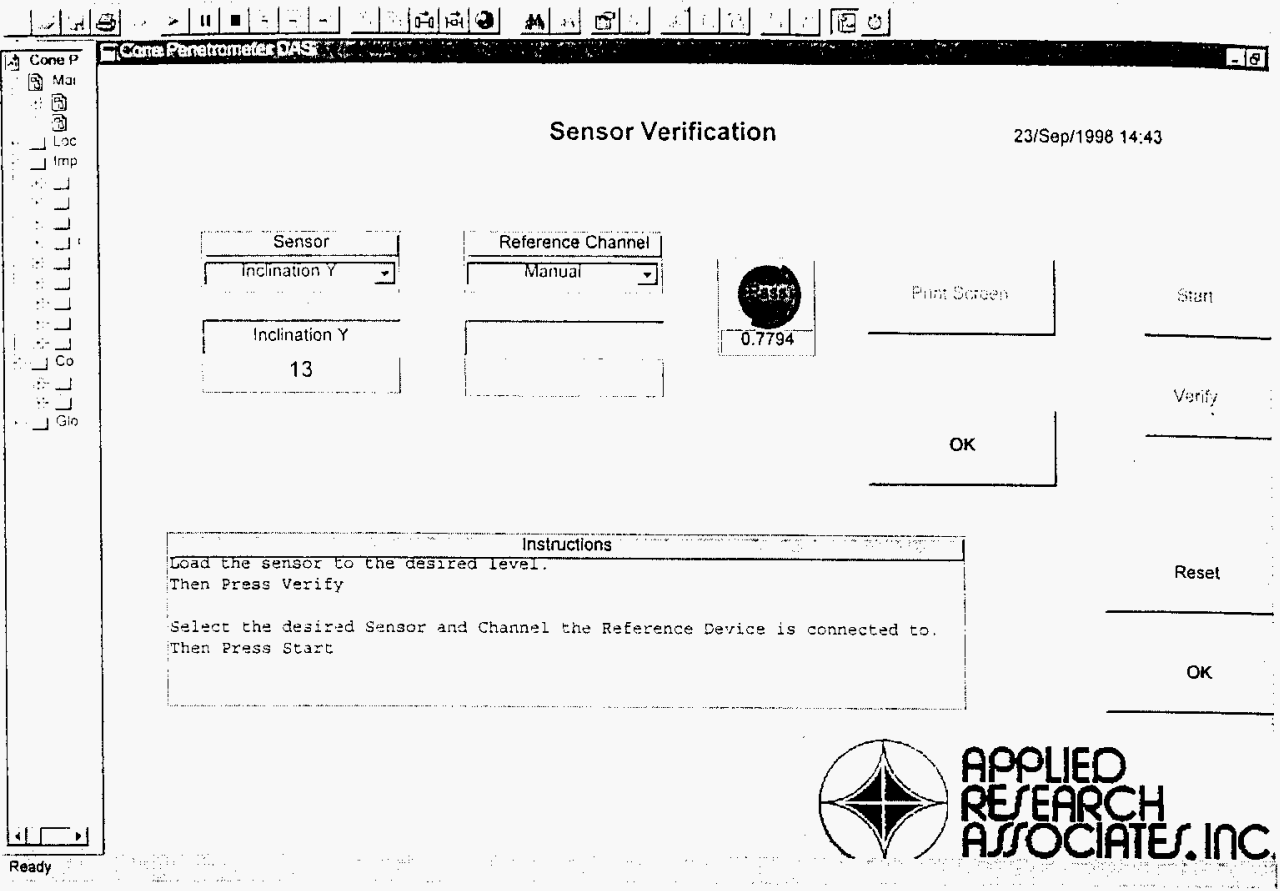




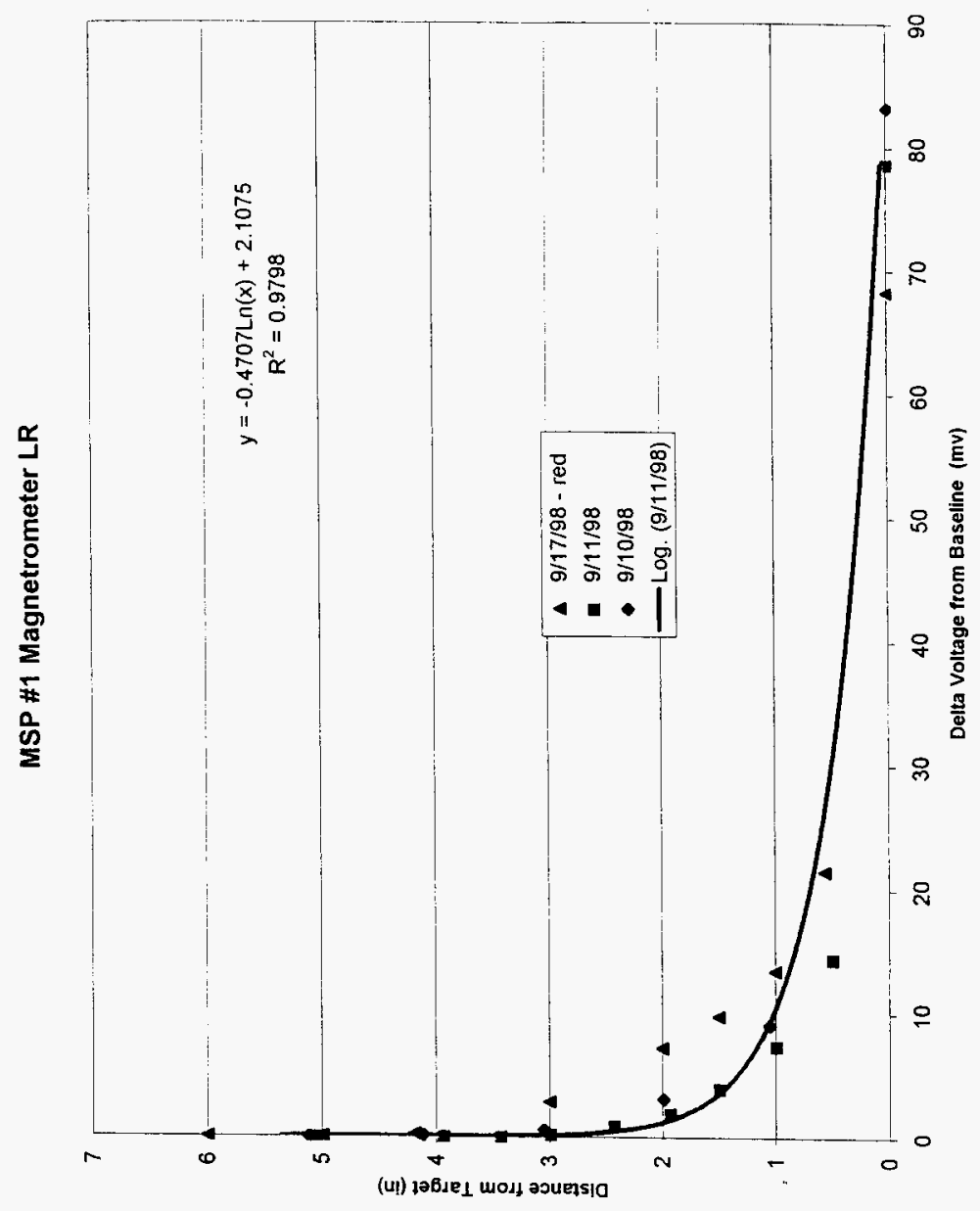

$49 / 72$ 


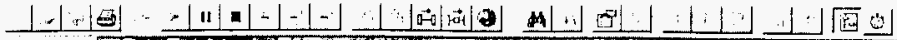

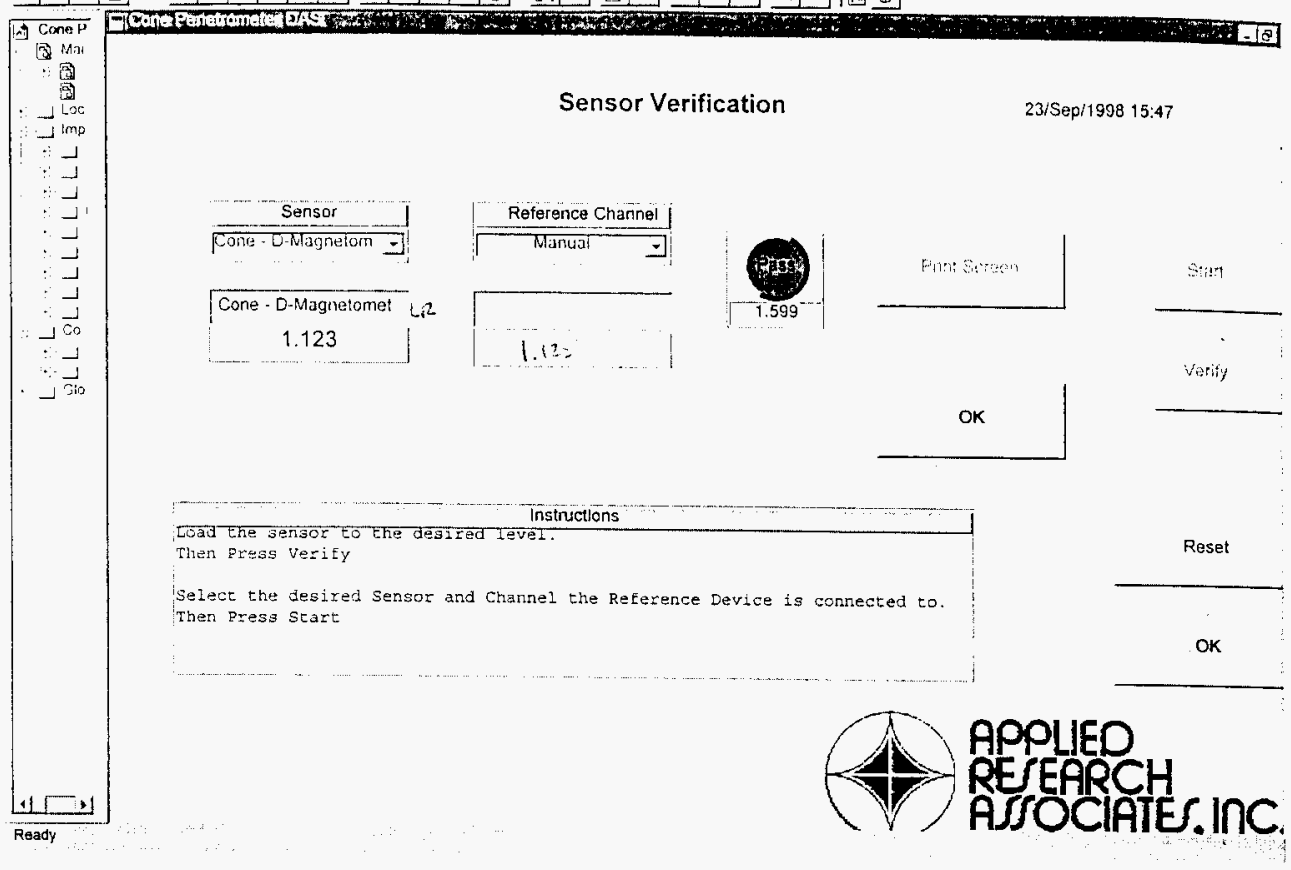




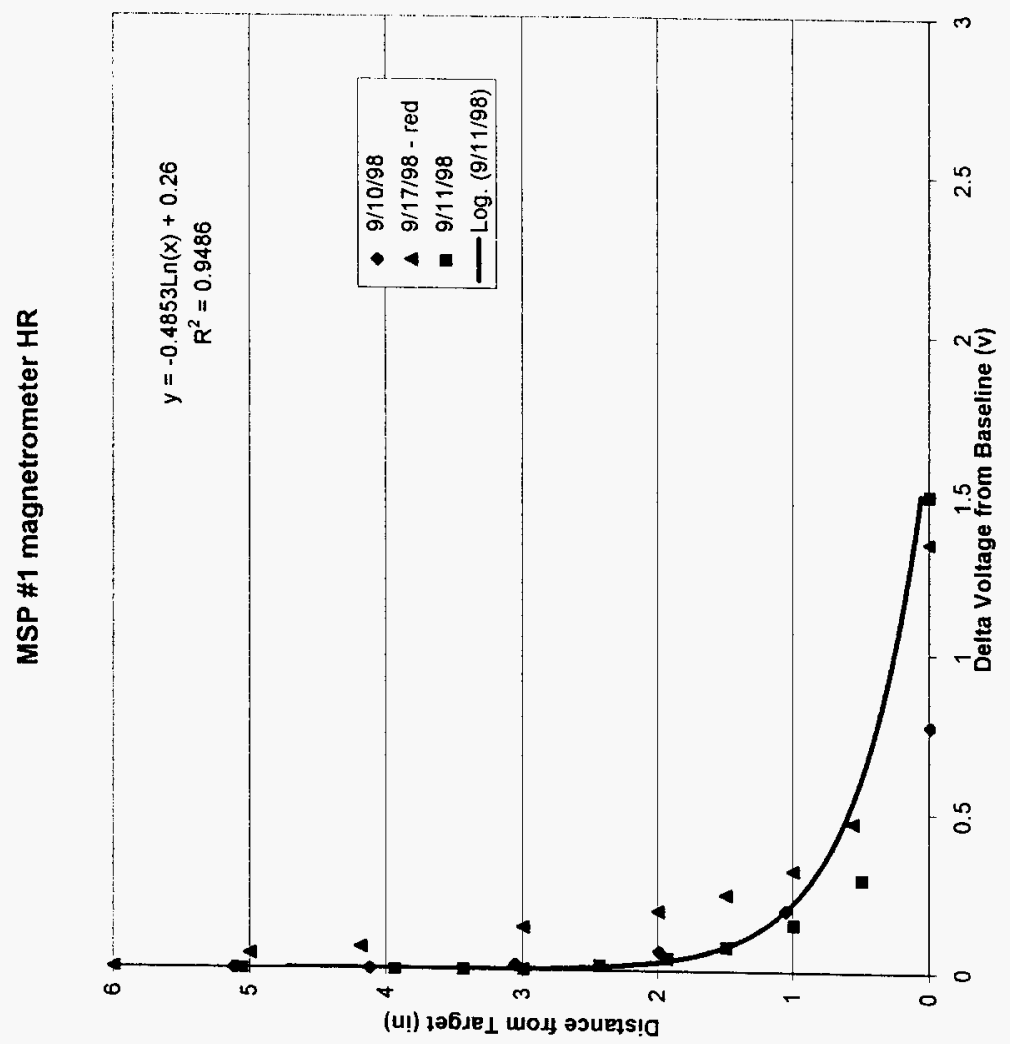




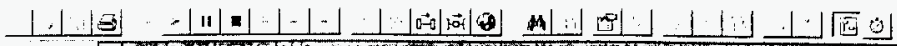

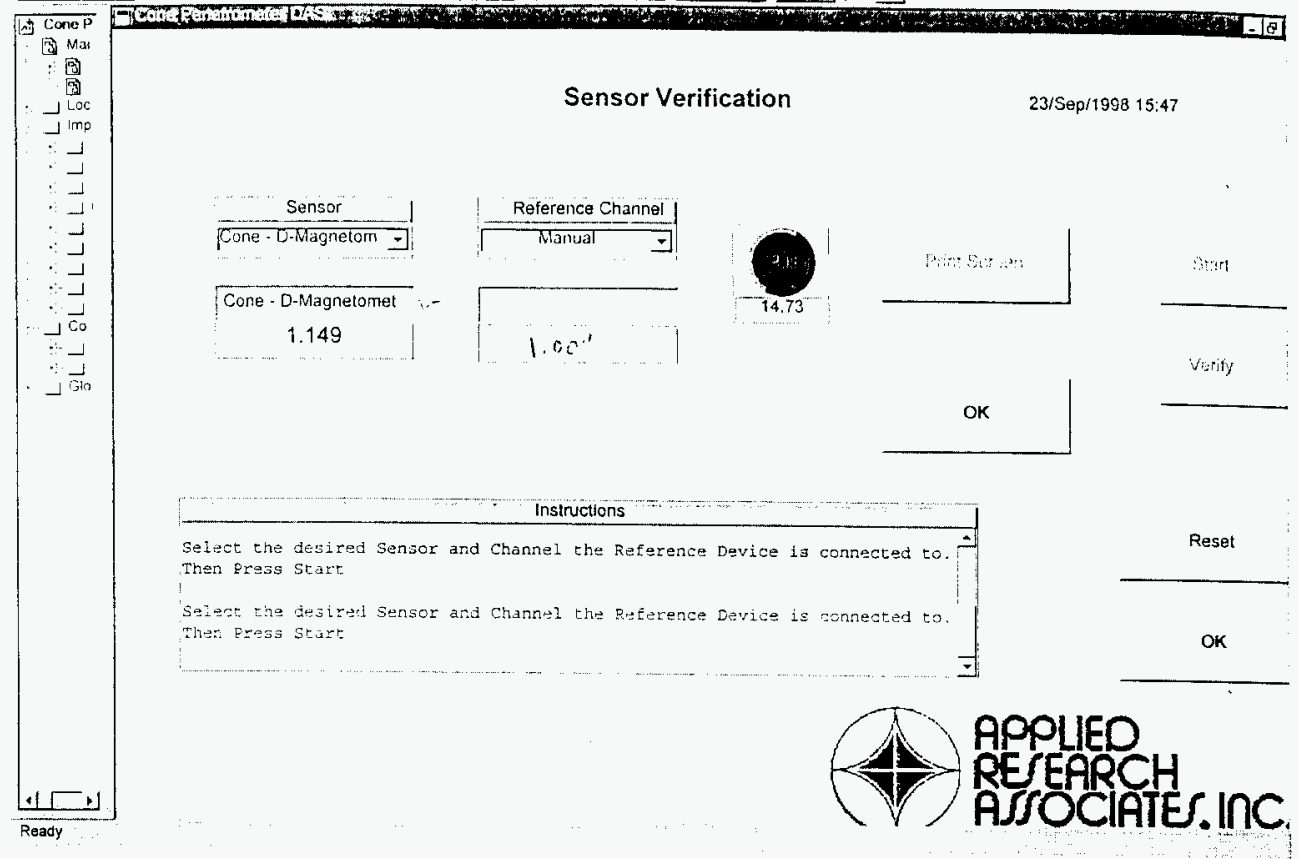




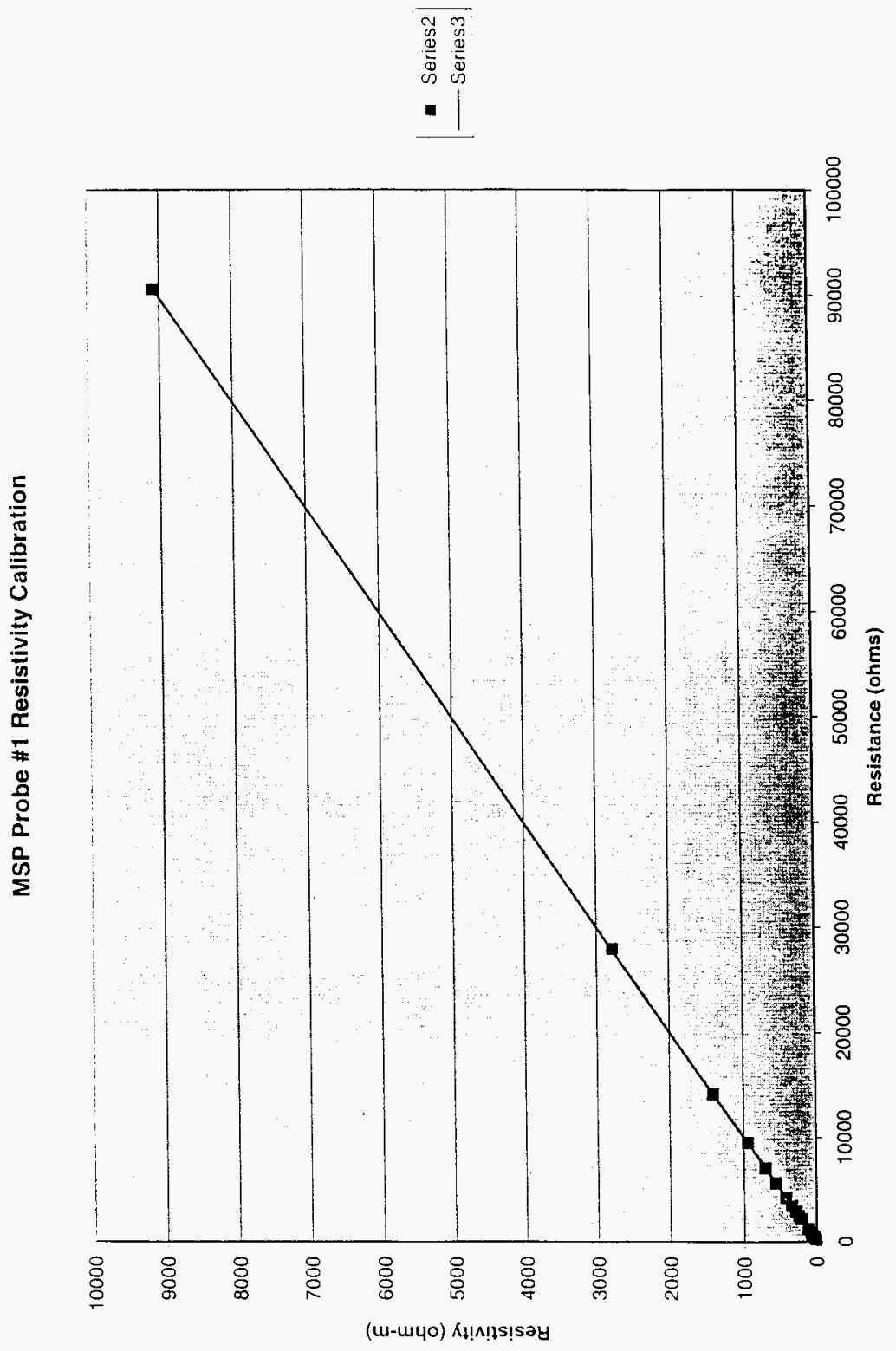

$54 / 72$ 


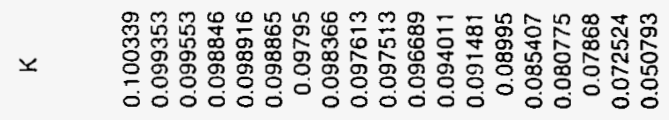

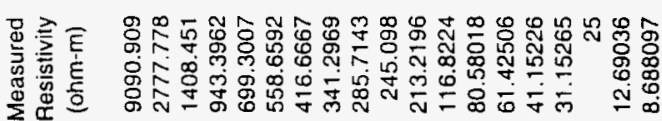

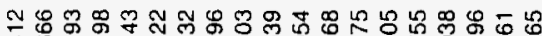

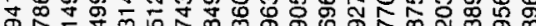
की 范 రิ

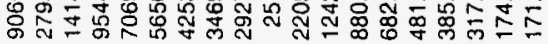

总

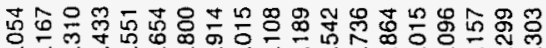

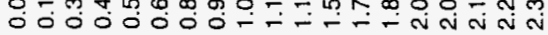

造

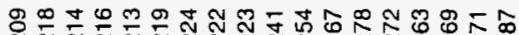

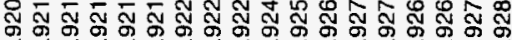

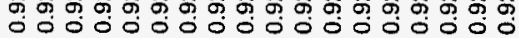

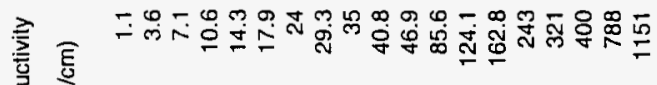

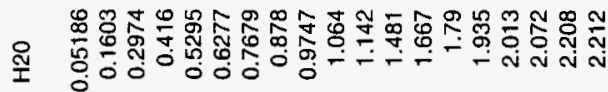

$\frac{1}{5}$

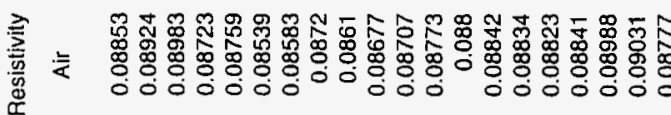

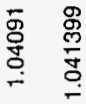

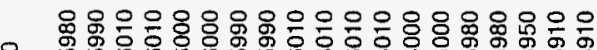

원

サั

क के

$\stackrel{\mathrm{N}}{\mathrm{N}} \stackrel{\mathrm{N}}{\mathrm{N}}$

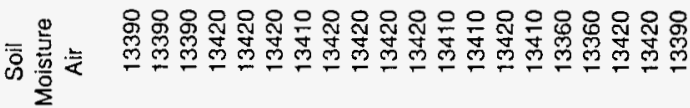

กิ

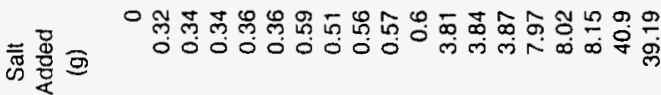

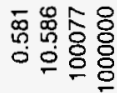




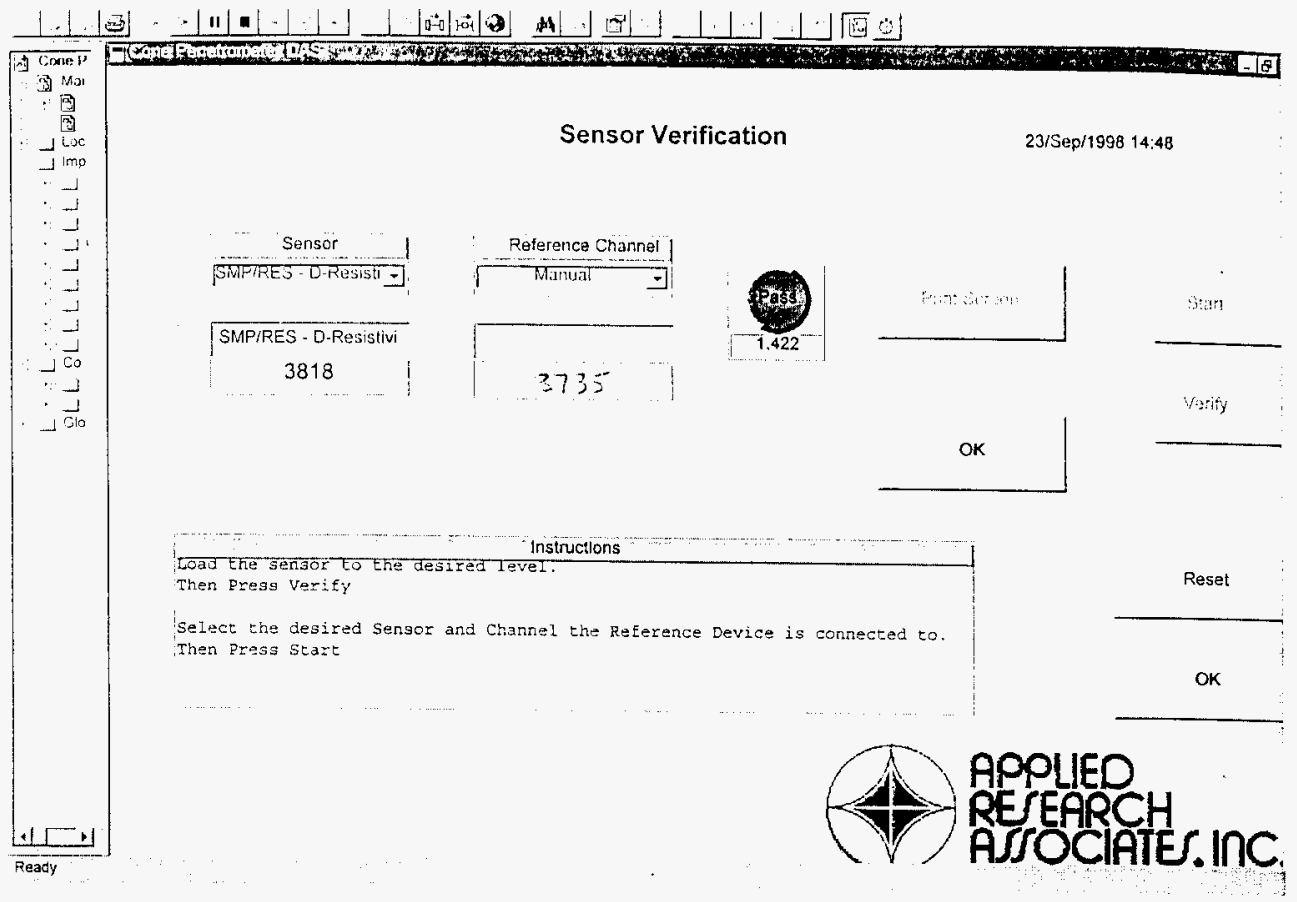

BEET …….... OOPY 


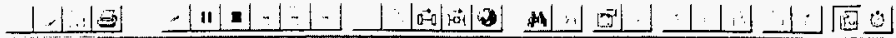

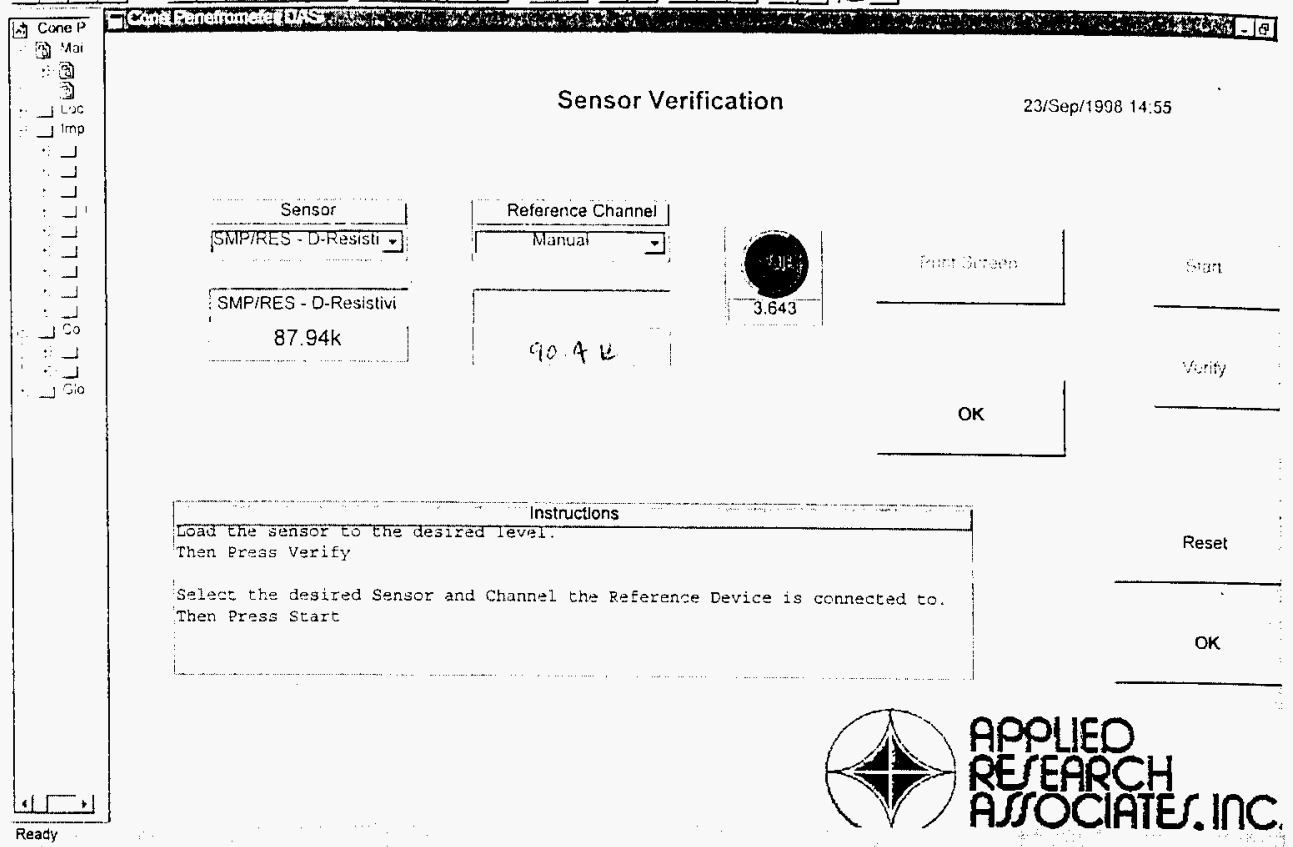




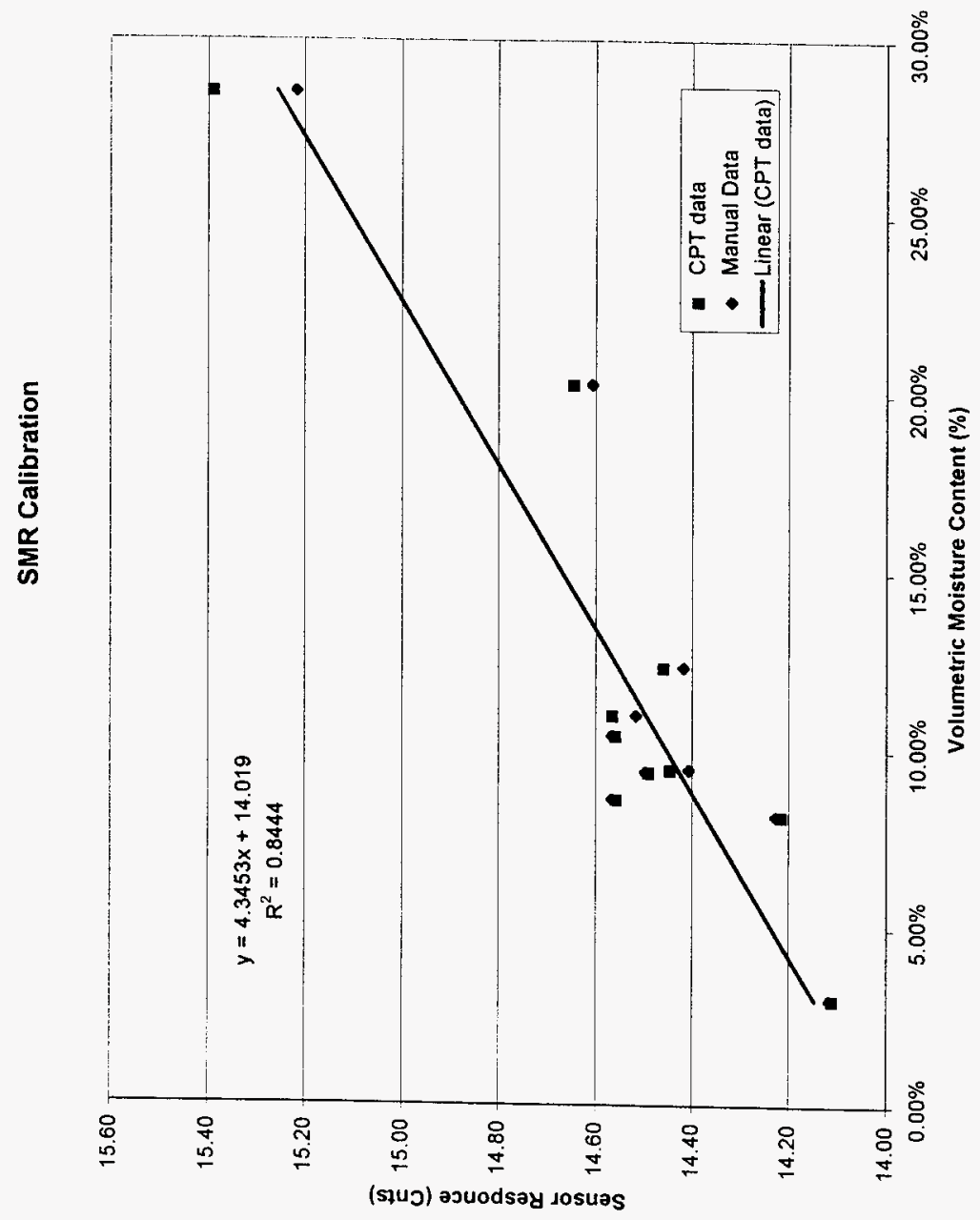




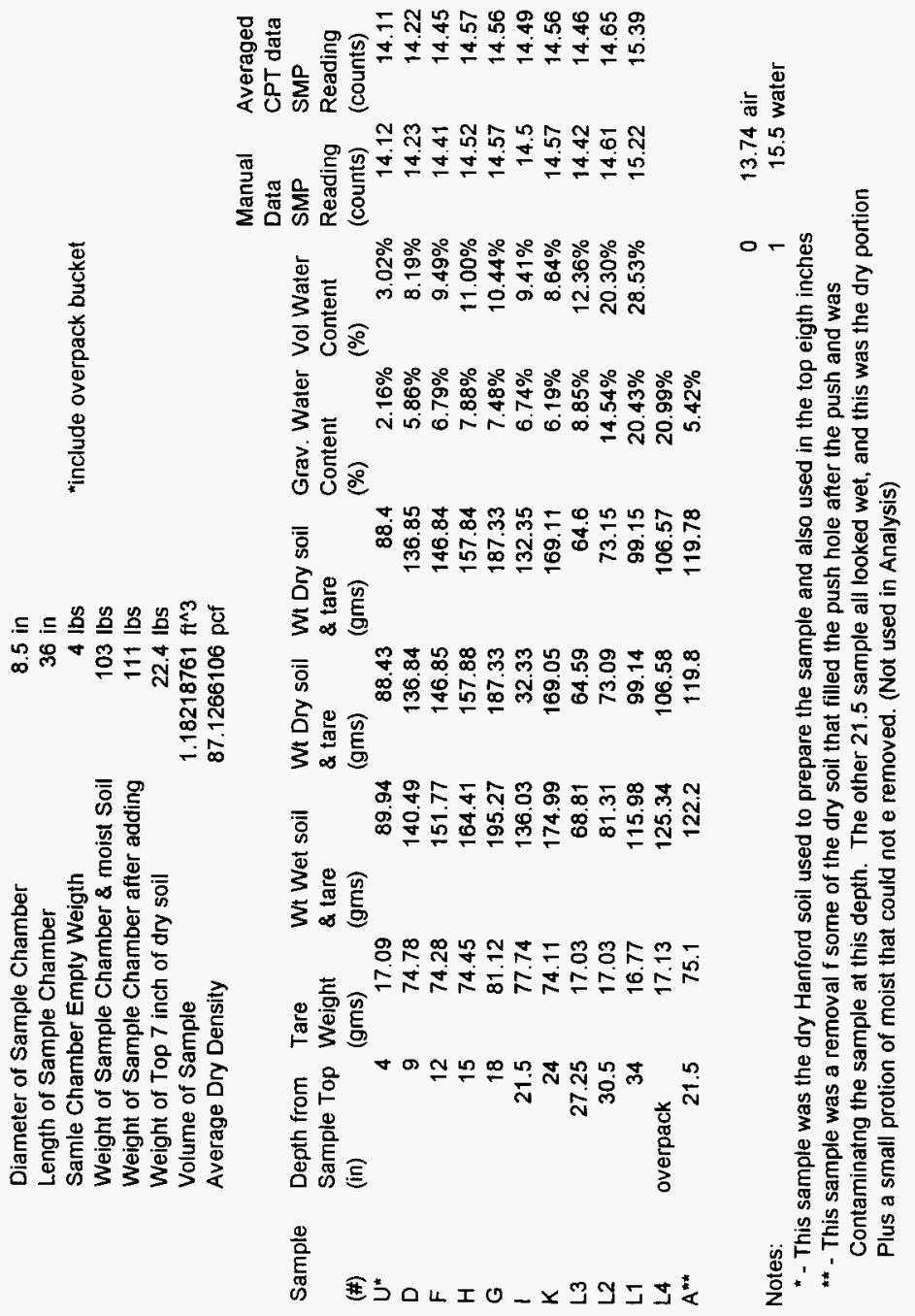




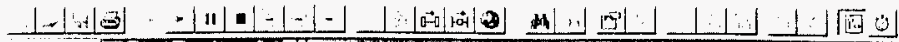

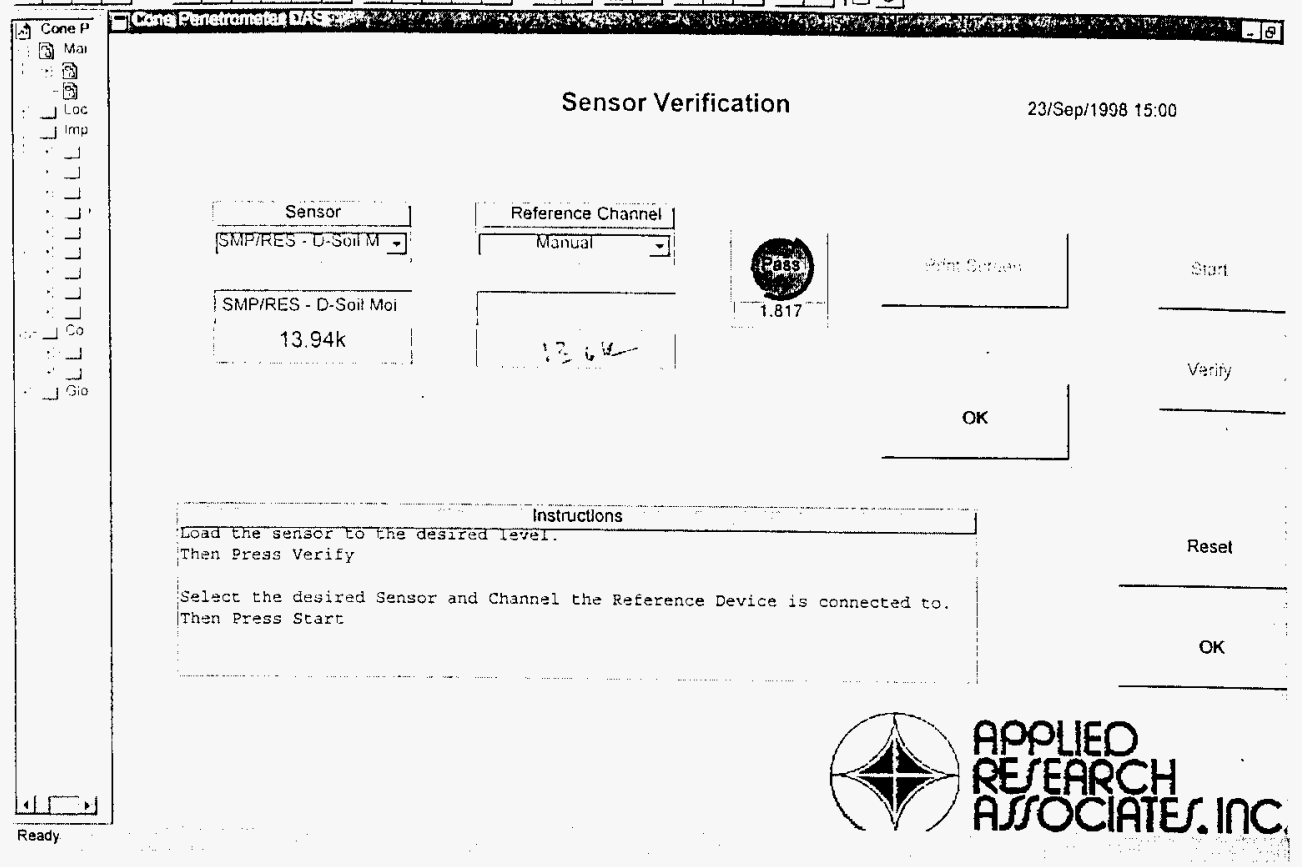




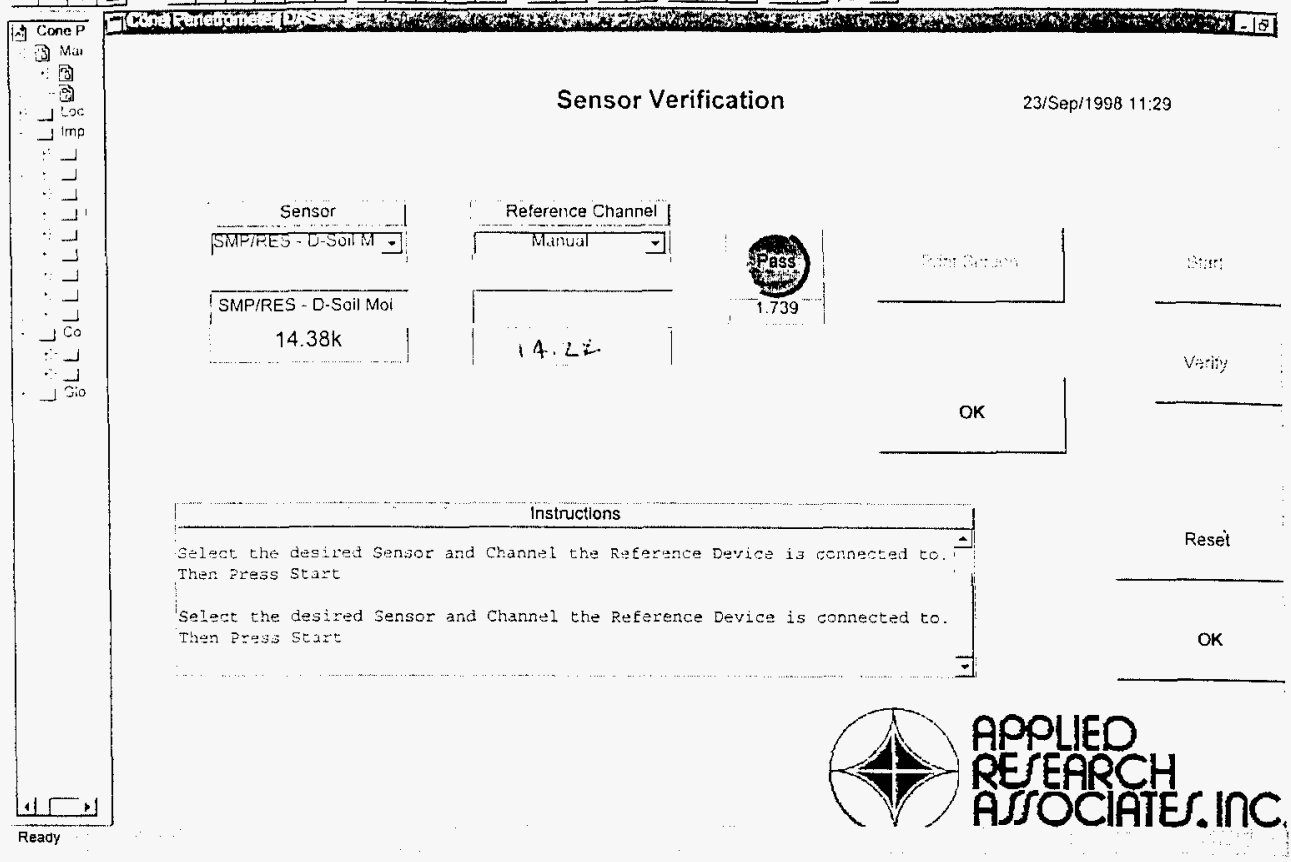




\section{ATTACHMENT 3 - GAMMA TEMPERATURE CORRECTION ALGORITHM}




\section{Description of the Temperature Correction Algorithm for the HTI Gamma Spectroscopy Detector System} William L. Dunn

Quantum Research Services, Inc.

Overview

14 July 1998

Consider a measured spectrum to be a collection of $N$ data pairs $\left(n, C_{n}\right)$, where

$n=1,2, \ldots, N$ is the channel number and $C_{n}$ is the number of counts in channel $n$. We identify a reference temperature, $T_{0}$, to which we wish to correct all measured spectra. We have chosen $T_{0}=302^{\circ} \mathrm{K}\left(84^{\circ} \mathrm{F}\right)$ but other values can be used.

Correcting a measured spectrum involves three steps. First, the channel numbers are multiplied by a gain shift, $\alpha$, and shifted by a displacement, $\beta$, whose values are determined by the temperature, $T$ (in ${ }^{\circ} \mathrm{K}$ ), at which the spectrum was collected and by $T_{0}$. Next, the counts are divided by the gain shift, $\alpha$, in order to keep the area under the spectral curve a constant. Finally, since the new channel numbers, $n^{\prime}$, will in general have noninteger values, it is necessary to interpolate/extrapolate the counts back to the integer channel numbers, $n$. The process is described in detail in the subsections below.

\section{Step 1. Transform Channel Numbers}

Given temperatures $T$ and $T_{0}$ in ${ }^{\circ} \mathrm{K}$, the parameters $\alpha$ and $\beta$ can be determined from the following expressions

$$
\alpha(T)=a_{1}+a_{2}\left(T-T_{0}\right)+a_{3}\left(T-T_{0}\right)^{2}+a_{4}\left(T-T_{0}\right)^{3}
$$

and

$$
\beta(T)=b_{0}\left(T-T_{0}\right)+b_{1}\left(T-T_{0}\right)^{2}+b_{3}\left(T-T_{0}\right)^{3}
$$

The model constants were determined for each of detectors 1 and 3 identified in Table 1 by fitting Eqs. (1) and (2) to data obtained at various temperatures between approximately 277 and $322^{\circ} \mathrm{K}$. For detector 1 the constants are

$$
\begin{aligned}
& a_{1}=0.962304, a_{2}=-0.485417 \times 10^{-2}, a_{3}=-0.885000 \times 10^{-4}, a_{4}=0.631425 \times 10^{-5} \\
& b_{1}=-0.108388, b_{2}=-0.207604 \times 10^{-2}, b_{3}=0.109398 \times 10^{-3}
\end{aligned}
$$

and for detector 3

$$
\begin{aligned}
& a_{1}=0.998277, a_{2}=0.265721 \times 10^{-2}, a_{3}=0.259709 \times 10^{-4}, a_{4}=-0.135721 \times 10^{-5} \\
& b_{1}=0.578803 \times 10^{-2}, b_{2}=0.180624 \times 10^{-3}, b_{3}=-0.151602 \times 10^{-4} .
\end{aligned}
$$

\begin{tabular}{|c|c|}
\hline Detector No. & Description \\
\hline$\overline{1}$ & Original NaI detector supplied by WES \\
\hline 2 & Alpha Spectra NaI detector, Serial Number 051298A \\
\hline
\end{tabular}

These constants were determined for $T_{0}=302^{\circ} \mathrm{K}$; new model constants must be determined if another reference temperature is used.

Table 1. Description of detectors 1, 2, and 3 . 
The variation of channel number corresponding to the spectral peaks for four photon energies $-356 \mathrm{keV}, 662$ $\mathrm{keV}, 1,173 \mathrm{keV}$, and $1,332 \mathrm{keV}$ - with detector temperature (as measured by a thermocouple mounted on the detector end) are shown in Figs. $1-4$ for detectors 1 and 3. Two temperature traverses were obtained for detector 1, one (a) on June 19,1998, and the other (b) on June 20-21, 1998. The two traverses yield qualitatively similar results but there are noticeable differences, which presumably are due to temperature history effects (rate of heating or cooling, etc.). It is clear that detector 3 is less sensitive to temperature variations than is detector 1 .

Once $\alpha$ and $\beta$ are obtained from Eqs. (1) and (2) the channel numbers $n$ are transformed into new (non-integer) channel numbers $n^{\prime}$, as follows

$$
n^{\prime}=\alpha(T) n+\beta(T) \text {. }
$$

Note that if $\alpha>1$, one or more values of $n^{\prime}$ may exceed $N$, the maximum number of channels. The third step, described later, will deal with this situation. For illustration, we show in Table 2, two sets of new channel numbers, $n^{\prime}$, for a spectrum of $N=10$ channels; the first set is for a compression, with $\alpha=0.95$ and $\beta=-0.5$, and the second set is for an expansion, with $\alpha=1.05$ and $\beta=0.5$.

Table 2. Hypothetical transformations for two sets of $\alpha$ and $\beta$.

\begin{tabular}{c|c|c}
$n$ & $n^{\prime}(\alpha<1)$ & $n^{\prime}(\alpha>1)$ \\
\hline 1 & 0.9 & 1.1 \\
2 & 1.4 & 2.6 \\
3 & 2.35 & 3.65 \\
4 & 3.3 & 4.7 \\
5 & 4.25 & 5.75 \\
6 & 5.2 & 6.8 \\
7 & 6.15 & 7.85 \\
8 & 7.1 & 8.9 \\
9 & 8.05 & 9.95 \\
10 & 9.0 & 11.0
\end{tabular}

\footnotetext{
\& The paperwork that came with this detector indicated 052098A; the detector itself is labeled 051898A.
} 

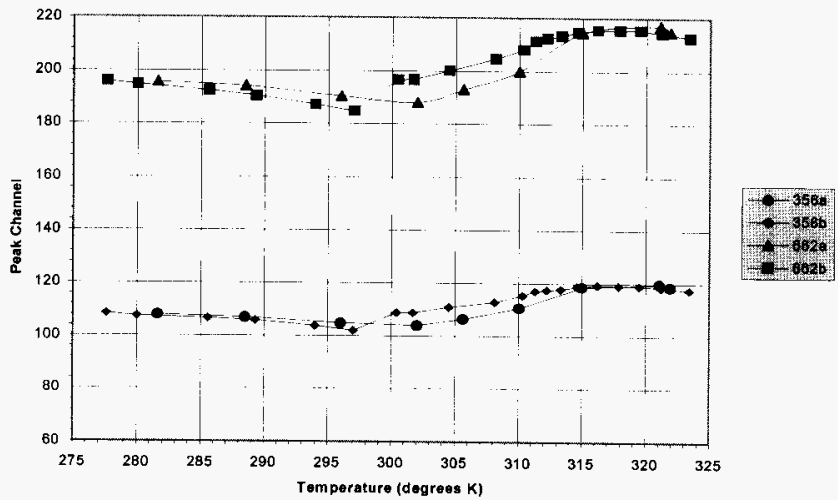

Figure 1. Variation of peak channel number with temperature for detector 1 at photon energies $356 \mathrm{keV}$ and $662 \mathrm{keV}$.
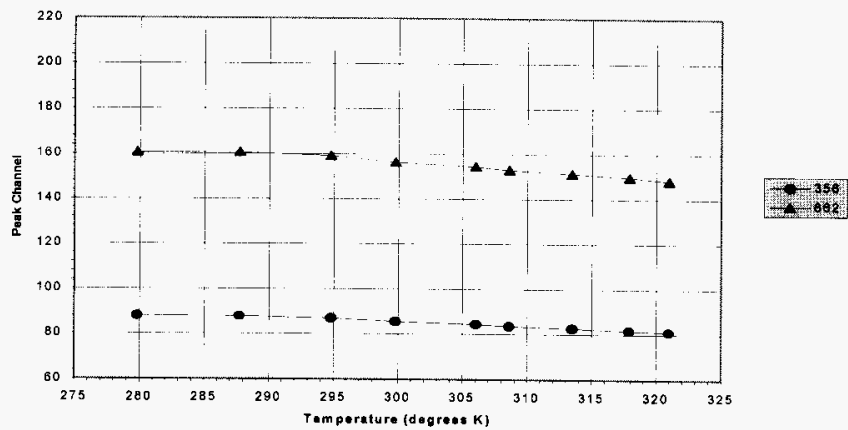

Figure 2. Variation of peak channel number with temperature for detector 3 at photon energies $356 \mathrm{keV}$ and $662 \mathrm{keV}$. 


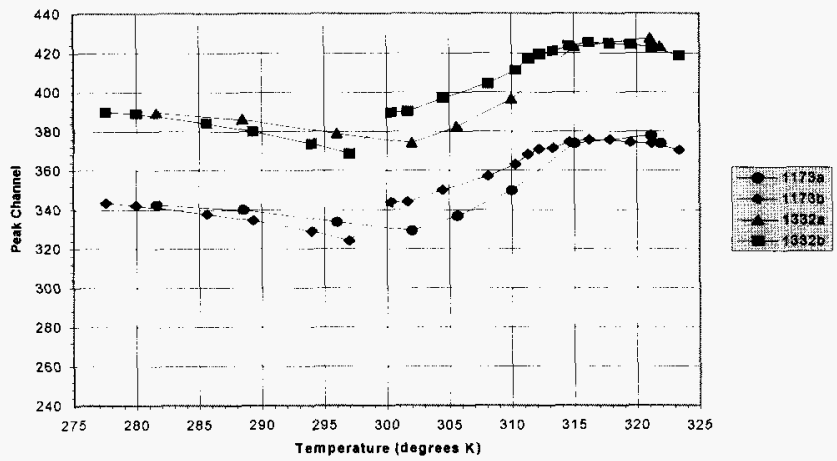

Figure 3. Variation of peak channel number with temperature for detector 1 at photon energies $1,173 \mathrm{keV}$ and $1,332 \mathrm{keV}$.
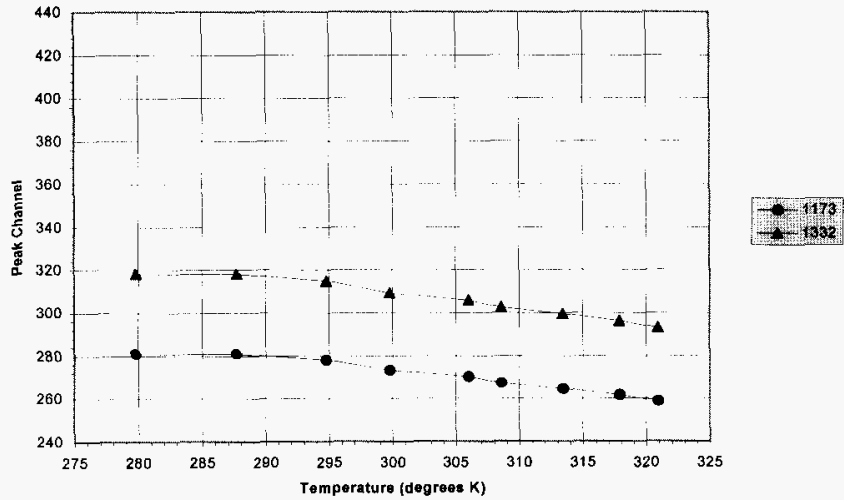

Figure 4. Variation of peak channel number with temperature for detector 3 at photon energies $1,173 \mathrm{keV}$ and $1,332 \mathrm{keV}$. 


\section{Step 2. Scale the Counts}

The second step is necessary in order for the integral under each peak to remain constant. In this step the counts in each channel are adjusted by a simple division, i.e.,

$$
C_{n}^{\prime}=\frac{C_{n}}{\alpha}, \text { for } n=1,2, \ldots, N \text {. }
$$

In the case of $\alpha>1$ each peak is spread over more channels and so the counts in each channel are reduced; for $\alpha<1$ each peak is shrunk into fewer channels and so the counts in each channel are increased, in order to preserved the same area.

\section{Step 3. Perform Linear Interpolation/Extrapolation}

At this point we have transformed the data pairs $\left(n, C_{n}\right)$ into the new data pairs $\left(n^{\prime}, C_{n}^{\prime}\right)$ by steps 1 and 2 .

However, the $n^{\prime}$ have, in general, non-integer values and so will not be treated or displayed properly as spectra. Thus, we must convert the counts $C_{n}^{\prime}$ to appropriate values at the original integer channel values, $n=1,2, \ldots, N$. This is done by linear interpolation/extrapolation of the nearest two transformed channels.

We first determine the two nearest $n^{\prime}$ points, call the lower one $j$ and the upper one $k$, to each value of $n=$ $1,2, \ldots, N$. We then interpolate/extrapolate the counts $C_{j}^{\prime}$ and $C_{k}^{\prime}$ to channel $n$. The following algorithm identifies for each $n$ the appropriate $j$ and $k$ values to use:

Begin with $n=1$, for which $j=1$ and $k=2$.

Proceed in order through $n=2,3, \ldots, N$

$$
\begin{aligned}
& \text { If } n<j \text {, keep the same } j \text { and } k \\
& \text { If } n^{\prime} \leq n \leq(n+1)^{\prime}, j=n^{\prime}, k=(n+1)^{\prime} \\
& \text { If } n>N^{\prime}, j=N-1, k=N
\end{aligned}
$$

Then, we apply the interpolation/extrapolation formula

$$
C_{n}^{\prime \prime}=C_{k}^{\prime}-\frac{k-n}{k-j}\left(C_{k}^{\prime}-C_{j}^{\prime}\right)
$$

to obtain the corrected counts, $C_{n}^{n}$, at integer channel $n$. Finally, since it is possible in some extrapolation cases for $C_{n}^{\prime \prime}$ to be negative, we apply

$$
\begin{aligned}
& D_{n}=C^{\prime \prime}, \text { if } C_{n}^{n} \geq 0 \\
& D_{n}=0, \text { if } C_{n}^{n}<0
\end{aligned}
$$

where $D_{\mathbf{n}}$ is the final corrected number of counts in spectrum channel $n$. 


\title{
CPP FIELD NOTES
}

\author{
Wednesday, 7 October 98
}

Goal: Test operation of modified soil sampler by obtaining 5 consecutive samples.

Witnesses: Willie Dickerson

Bob Jones

Dean Hagmann
ARA

Sand \& Sage

Cogema Engineering

- Pushed SSP down existing $25 \mathrm{ft}$ hole using M/I tip. The new latched held the insert in place with push pressures of over $30 \mathrm{Klbs}$.

- Attempted first sample at 24'. M/I tip easily unlatched. The tip was quite warm when it got to the surface. Loaded Sample Chamber. The Sample Chamber is tapered on the lower inner edge, there are no air release holes in the tip of the chamber, and the tip was in place as a cap for the top of the sampler.

- It took a little wiggling, but the sampler latched. Pushed 8 inches. The inner poles lowered with the rods showing it was latched and remained latched.

Didn't use brushes.

- Insert easily unlatched. Sample Chamber was only half full. Sample \#1. The soil was tightly packed into sampler chamber.

- Lowered M/I tip backed down and it easily latched. Stayed in place with push forces of up to $40 \mathrm{klbs}$.

- $\mathrm{M} / \mathrm{I}$ tip easily unlatched. O-ring around tip was sheared and there was dirt around the tip. ( 2 pictures)

- Lowered sample chamber. The insert gets caught about 3-4inches above its latch position. A little wiggling will lower it completely. Latched in easily, no brushes. There was no tip in the back of the sample chamber to see if it would fill completely.

- Pushed 8-9". Unlatched easily. Chamber not full (1.5 inches from top), soil packed in chamber. Sample \#2. It seems the soil is so tightly packed in the sample chamber and nosecone that additional soil is pushed to the side rather than up the chamber. 
- Lowered M/I tip, wiggled past where it gets caught and it latched easily. Pushed another rod.

- M/I tip released easily, again o-ring sheared and soil caught around tip. (2 pictures)

- Lowered sample chamber, latched easily, pushed 8 inches.

- Removed sample chamber, still not full. Sample \#3. 1" from top. Sent sample chamber back down, latched easily.

- Pushed another 8 inches, Unlatched just fine. Chamber only $1 / 2$ full. Soil very compressed, had to chisel out with screwdriver. Sample \#4.

- Relatched M/I tip, pushed another rod, pressures of $>45 \mathrm{klbs}$. Unlatched easily.

- Lowered and latched sampler chamber. Pushed 10-12" (Only 8" should be needed to fill chamber). Still didn't fill chamber. Sample \# 5. It's not push distance, its soil compression and friction that is preventing the sample chamber from filling.

- Overall, the Modified SSP worked smoothly with no problems (except not filling the chamber completely). The latch latched into place easily with each try and, with a tug or two, unlatched just as easily. The unit always remained latched while pushing with pressures of up to $>45,000 \mathrm{lbs}$. 
1. Inclination Calibration Curves
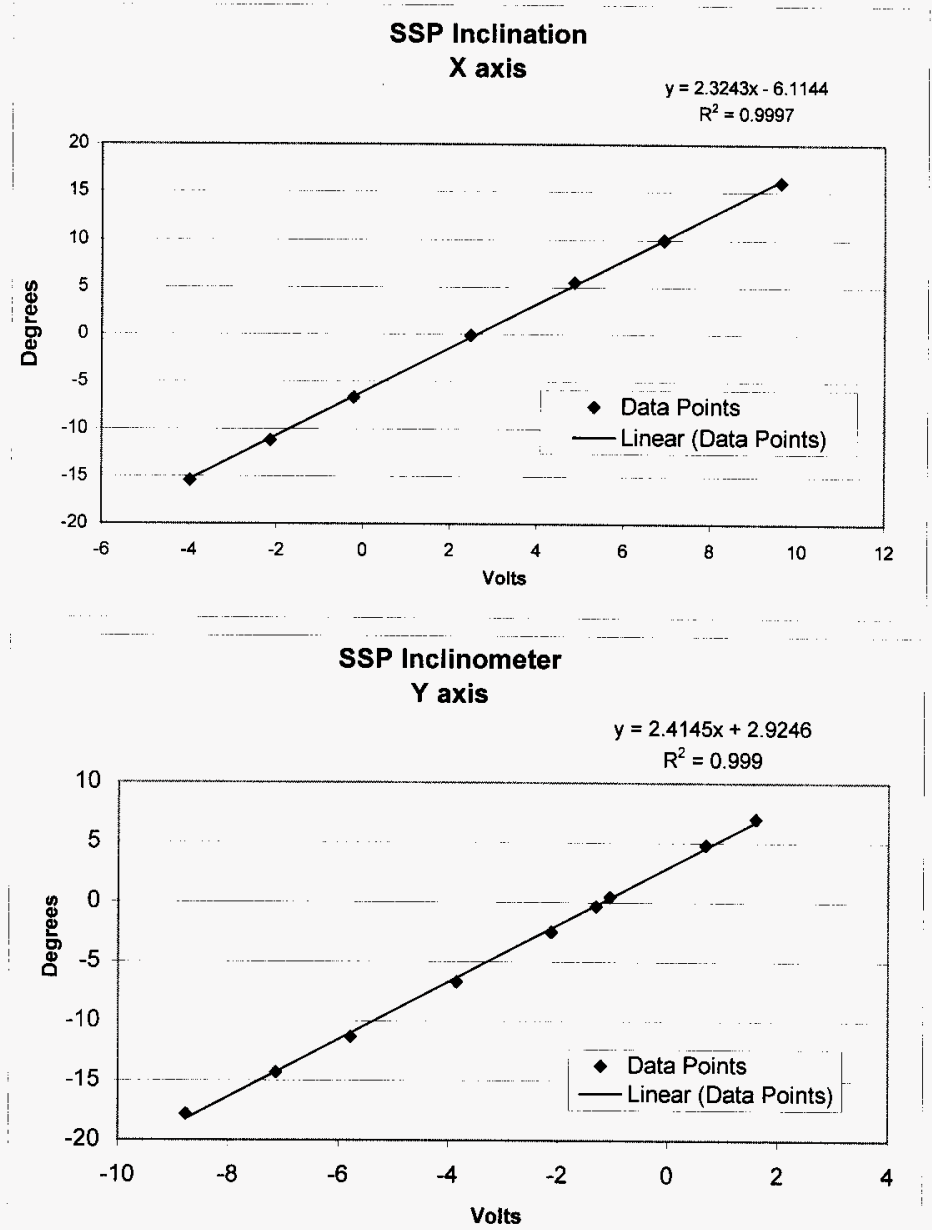
2. Magnetometer Calibration

\section{SSP Magnetometer Calibration (10/22)}

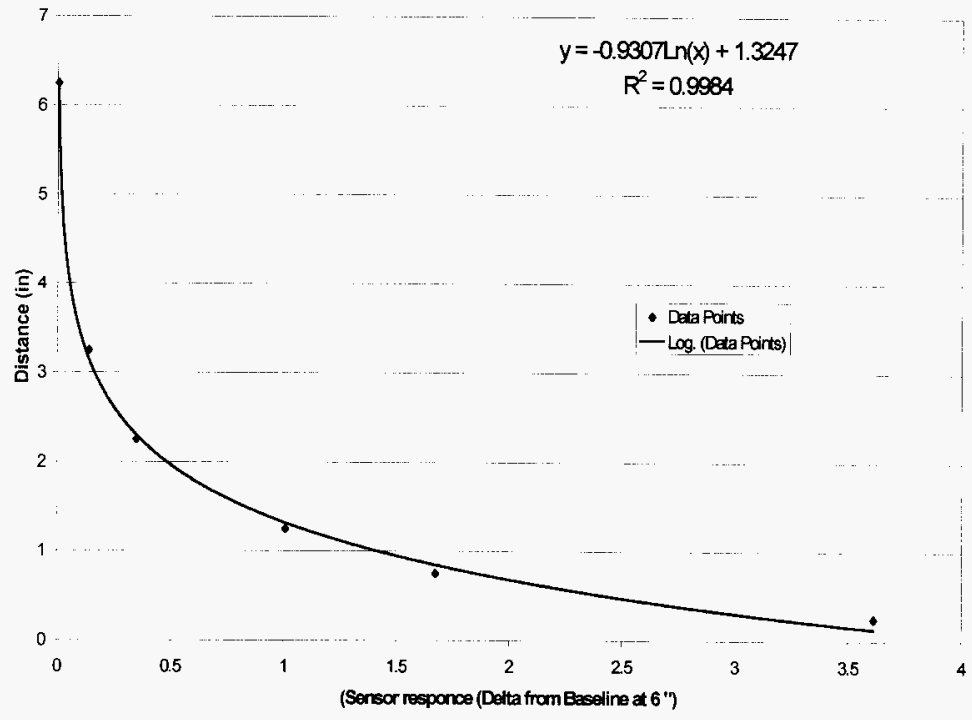




\section{DISTRIBUTION SHEET}

\begin{tabular}{|c|c|c|c|c|c|}
\hline \multirow{2}{*}{$\begin{array}{l}\text { To } \\
\text { Distribution }\end{array}$} & \multirow{2}{*}{\multicolumn{3}{|c|}{$\begin{array}{l}\text { From } \\
\text { Numatec Hanford Co., Project } \\
\text { Definition }\end{array}$}} & \multicolumn{2}{|c|}{ Page 1 of 1} \\
\hline & & & & \multicolumn{2}{|c|}{ Date $10 / 23 / 98$} \\
\hline \multirow{2}{*}{\multicolumn{4}{|c|}{$\begin{array}{l}\text { Project Title/Work Order } \\
\text { HTI Cone Penetrometer Probes: Developmental Test Report } \\
\text { (HNF-3560, Rev. 0) }\end{array}$}} & \multirow{2}{*}{\multicolumn{2}{|c|}{$\begin{array}{ll}\text { EDT No. } & 622818 \\
\text { ECN No. } & \text { N/A }\end{array}$}} \\
\hline & & & & & \\
\hline Name & MSIN & $\begin{array}{l}\text { Text } \\
\text { With All } \\
\text { Attach. }\end{array}$ & Text Only & $\begin{array}{l}\text { Attach./ } \\
\text { Appendix } \\
\text { Only }\end{array}$ & $\begin{array}{l}\text { EDT/ECN } \\
\text { Only }\end{array}$ \\
\hline GL Troyer & $\mathrm{T} 6-50$ & $x$ & & & \\
\hline WS Cal1 away & S3-90 & $x$ & & & \\
\hline DF Iwatate & $\mathrm{R} 2-89$ & $x$ & & & \\
\hline R Root & \multicolumn{2}{|l|}{$\mathrm{R} 2-53$} & \multicolumn{2}{|c|}{$X(c v r)$} & \\
\hline AF Noonan & $\mathrm{R} 2-89$ & $x$ & & & \\
\hline JM Zimmer (2) & $B 1-42$ & $x$ & & & \\
\hline GS Leshikar & SO-08 & & $X(c \vee r)$ & & \\
\hline Central Files (1) & $B 1-07+17=09$ & $x$ & & & \\
\hline HTI Project Files (1) & $\mathrm{R} 1-29$ & $x$ & & & \\
\hline DOE/RL Reading Room & \multirow[t]{2}{*}{$\mathrm{Hz}-53$} & $x$ & & & \\
\hline (CP_DTR_O.DIS) & & & & & \\
\hline
\end{tabular}

